\title{
Electronic Properties and Dissociative Photoionization of Thiocyanates. Part II. Valence and Shallow-Core (Sulfur and Chlorine 2p) Regions of Chloromethyl Thiocyanate, $\mathrm{CH}_{2} \mathrm{ClSCN}$
}

\author{
Lucas S. Rodríguez Pirani, ${ }_{5}^{\dagger}$ Mariana Geronés, ${ }^{+}$Carlos O. Della Védova, ,+,, ${ }^{,+}$osana M. Romano, ${ }^{+}$
} Adolfo Fantoni, ${ }^{\varsigma}$ Reinaldo Cavasso-Filho, " Chunping Ma, ${ }^{\perp}$ Maofa Ge, ${ }^{\perp}$ and Mauricio F. Erben ${ }^{*,}$

${ }^{+}$CEQUINOR (UNLP-CONICET, CCT La Plata), Departamento de Química, Facultad de Ciencias Exactas, Universidad Nacional de La Plata, CC 962, La Plata (CP 1900), República Argentina

${ }^{\ddagger}$ Laboratorio de Servicios a la Industria y al Sistema Científico (LaSeISiC, UNLP-CIC-CONICET, Camino Centenario e/505 y 508, (1903) Gonnet, República Argentina

${ }^{\S}$ Instituto de Física La Plata, Departamento de Física, Facultad de Ciencias Exactas, Universidad Nacional de La Plata, 49 y 115 , La Plata, Buenos Aires, República Argentina

"Universidade Federal do ABC, Rua Catequese, 242, CEP 09090-400, Santo André, São Paulo, Brazil

${ }^{\perp}$ State Key Laboratory for Structural Chemistry of Unstable and Stable Species, Beijing National Laboratory for Molecular Sciences (BNLMS), Institute of Chemistry, Chinese Academy of Sciences, Beijing 100190, Peoples Republic of China

Supporting Information

ABSTRACT: A combination of photoelectron spectroscopy and synchrotron based photoelectron photoion coincidence (PEPICO) spectra has been applied to investigate the electronic structure and the dissociative ionization of the $\mathrm{CH}_{2} \mathrm{ClSCN}$ molecule in the valence region. The PES is assigned with the electronic structure calculations at the outer-valence Green's function and symmetry adapted cluster/ configuration interaction (SAC-CI) levels offer an explanation of our experimental results. Upon vacuum ultraviolet irradiation the low-

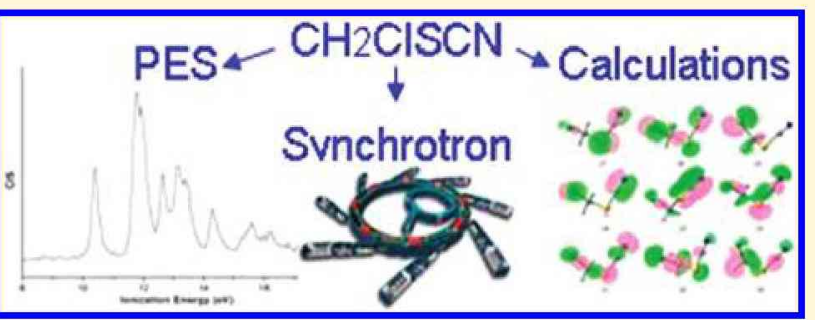
lying radical cation, located at $10.39 \mathrm{eV}$ is formed. The molecular ion is observed in the time-of-flight mass spectra, together with the $\mathrm{CH}_{2} \mathrm{SCN}^{+}$and $\mathrm{CH}_{2} \mathrm{Cl}^{+}$daughter ions. The total ion yield spectra have been measured in the $\mathrm{S} 2 \mathrm{p}$ and $\mathrm{Cl} 2 \mathrm{p}$ regions and several channels have been determined in dissociative photoionization events for the coreexcited species. Thus, by using time-of-flight mass spectrometry and synchrotron radiation the relative abundances of the ionic fragments and their kinetic energy release values were obtained from both PEPICO and photoelectron photoion photoion coincidence spectra. Possible fragmentation processes are discussed and compared with that found for the related $\mathrm{CH}_{3} \mathrm{SCN}$ species.

\section{INTRODUCTION}

Thiocyanates are well-known in the area of organo-sulfur chemistry and widely used as key intermediates in various organic reactions and as biocides. ${ }^{1-3}$ Thiocyanates are also considered to be an important class of compounds found in some anticancer natural products formed by deglycosylation of glucosinolates derived from cruciferous vegetables. ${ }^{4}$ In particular, the chloromethyl thiocyanate, $\mathrm{CH}_{2} \mathrm{ClSCN}$, shows excellent fungicidal, nematocidal, and bactericidal activity. It is also used as a starting material in the synthesis of pesticides. $\mathrm{CH}_{2} \mathrm{ClSCN}$ is used as an intermediate for synthesis of 2-(thiocyanomethylthio)-benzothiazole, which is widely used as fungicide in the leather making industry. ${ }^{5,6} \mathrm{CH}_{2}$ ClSCN was used to introduce the S-chloromethyl group in several compounds, ${ }^{7,8}$ and recently it found applications in the preparation of thiocyanate functionalized ionic liquids.

In spite of the great importance of this molecule, few spectroscopic data have been reported for the title species. The vibrational properties of liquid $\mathrm{CH}_{2} \mathrm{ClSCN}$ have been studied by Crowder. ${ }^{10,11}$
The Raman spectrum supports the conclusion that only the trans (chlorine atom and SCN group in a mutual trans orientation) $C_{s}$ conformer is present in the liquid at room temperature. The photoelectron spectrum of gaseous $\mathrm{CH}_{2} \mathrm{CISCN}$ was first recorded by Mölder et al. ${ }^{12}$ and a molecular orbital assignment for the outer valence electron distribution was proposed on the basis of $\mathrm{CNDO} / 2$ semiempirical calculations.

The electronic properties of shallow- and inner-core level electrons in chalcogenide species (molecules belonging to the XVI Main Group) has been studied by our group. Thus, sulfenylcarbonyl compounds, like the penta-atomic $\mathrm{FC}(\mathrm{O}) \mathrm{SCl}^{13}$ and $\mathrm{ClC}(\mathrm{O}) \mathrm{SCl}^{14}$ species, have been studied by using synchrotron radiation in the $100-1000 \mathrm{eV}$ range, and their ionic fragmentation after electronic decay has been analyzed. We have also

\footnotetext{
Received: August 25, 2011

Revised: $\quad$ November 16, 2011

Published: November 21, 2011
} 
studied other members of this family such as $\mathrm{CH}_{3} \mathrm{C}(\mathrm{O}) \mathrm{SH}^{15}$ $\mathrm{ClC}(\mathrm{O}) \mathrm{SCH}_{2} \mathrm{CH}_{3},{ }^{16}$ and $\mathrm{CH}_{3} \mathrm{OC}(\mathrm{O}) \mathrm{SCl}^{17}$ More recently, we have succeeded in analyzing the electronic structure and ionic dissociation induced by photon absorption in the outermost valence region by using a combined experimental approach that includes HeI photoelectron spectroscopy and photoionization under the action of synchrotron radiation in the $10.0-22.5 \mathrm{eV}$ region. ${ }^{18-20}$

On the basis of previous studies by Hitchcock et al., ${ }^{21}$ we also investigated the ionic dissociation of the simple thiocyanate $\mathrm{CH}_{3} \mathrm{SCN}$ molecule at the $\mathrm{S} 2 \mathrm{p}$ edge by using synchrotron radiation. ${ }^{22}$ Here, continuing with the study of thiocyanate species, we report a study of the photon impact excitation and dissociation dynamics of $\mathrm{CH}_{2}$ ClSCN excited at the $\mathrm{S} 2 \mathrm{p}$ and $\mathrm{Cl} 2 \mathrm{p}$ levels by using synchrotron radiation and multicoincidence PEPICO (photoelectron photoion coincidence) and PEPIPICO (photoelectron photoion photoion coincidence) techniques. Moreover, the outermost valence electronic structure has been studied by using the $\mathrm{He}(\mathrm{I})$ PES and high-level quantum chemical calculations including the outer-valence Green's function (OVGF) and SAC-CI methods.

\section{EXPERIMENTAL SECTION}

Hazards. When heated to decomposition or on contact with mineral acids, chloromethyl thiocyanate releases highly toxic fumes.

Synchrotron radiation was used at the Laboratório Nacional de Luz Síncrotron (LNLS), Campinas, São Paulo, Brazil. ${ }^{23}$ Linearly polarized light monochromatized by a toroidal grating monochromator (available at the TGM beamline in the range $12-300 \mathrm{eV}){ }^{24}$ intersects the effusive gaseous sample inside a high vacuum chamber, with base pressure in the range $10^{-8}$ mbar. The gas-jet needle was mounted on a $x y z$ manipulator and the optimal position determined by scanning and obstructing the light by the needle and monitoring the light intensity in perpendicular positions of the beam with a light-sensitive diode. The fwhm of the light beam was determined to be $1 \mathrm{~mm} .{ }^{25}$ During the experiments the pressure was maintained below $5 \times 10^{-6} \mathrm{mbar}$. The resolution power is better than 400 in the TGM beamline at the LNLS. The energy calibration was established by means of the $S 2 \mathrm{p} \rightarrow 6 \mathrm{a}_{1 \mathrm{~g}}$ and $\mathrm{S} 2 \mathrm{p} \rightarrow 2 \mathrm{t}_{2} \mathrm{~g}$ absorption resonances in $\mathrm{SF}_{6}{ }^{26}$ High-purity vacuum-ultraviolet photons were used in the $12-$ $21.5 \mathrm{eV}$ region, the problem of contamination by high-order harmonics being suppressed by using a gas-phase harmonic filter. ${ }^{27-29}$ The intensity of the emergent beam was recorded with a light-sensitive diode. The ions produced by the interaction of the gaseous sample with the light beam were detected using a time-of-flight (TOF) mass spectrometer of the Wiley-McLaren type for both PEPICO and PEPIPICO measurements. ${ }^{30,31}$ This instrument was constructed at the Institute of Physics, Brasilia University, Brasilia, Brazil. ${ }^{32}$ The spectrometer is cylindrically symmetric and the axis of the TOF spectrometer was perpendicular to the photon beam and parallel to the plane of the storage ring. Electrons were accelerated to a multi channel plate (MCP) and recorded without energy analysis. This event starts the flight time determination process of the corresponding ion, which is consequently accelerated to another MCP. Two grids are used to define the extraction region. Besides, an important characteristic of the apparatus is that on the rear side of the grids in the extraction region, lenses are mounted to improve detection efficiency of electrons and ions. The characteristics and performance of this electron-ion coincidence TOF spectrometer has been reported elsewhere. ${ }^{25}$

The average kinetic energy release (KER) values of the fragments were calculated from the coincidence spectra by assuming an isotropic distribution of the fragments and that they are perfectly

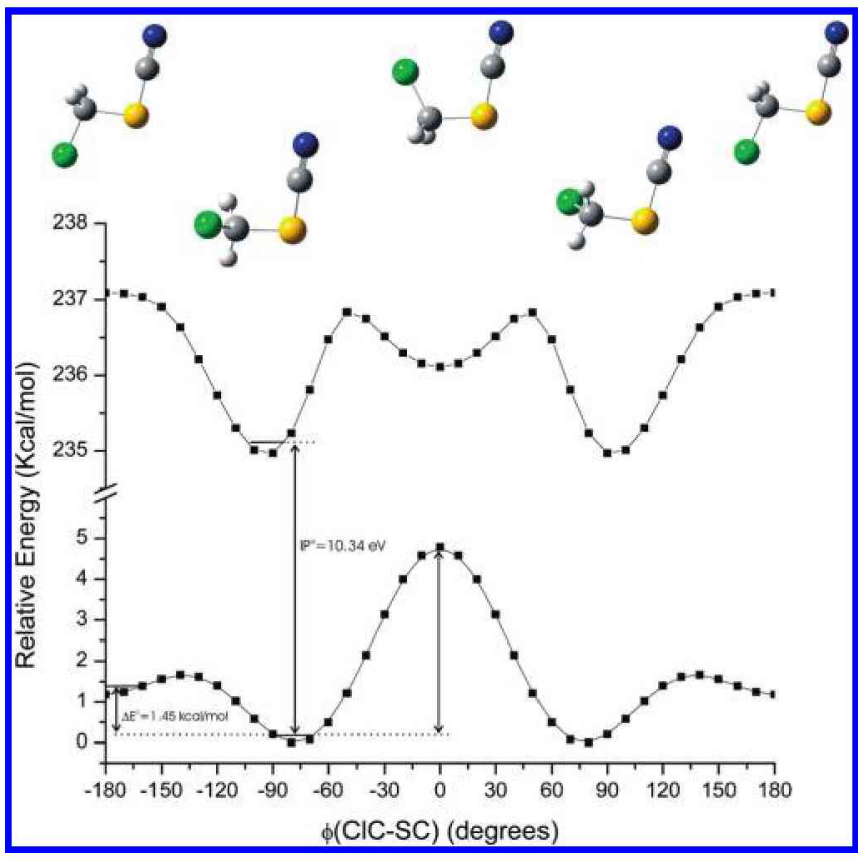

Figure 1. Potential energy curve computed $\left[\operatorname{CCSD}(\mathrm{T}) / 6-311++\mathrm{G}^{* *}\right]$.

space focused and the electric field applied in the extraction region is uniform. ${ }^{33}$ Under these conditions, the energy release in the fragmentation process can be determined from the peak width (fwhm). ${ }^{34}$ Deviations from ideal conditions always increase the peak width, thus the values calculated are upper bounds. Santos et al. ${ }^{35}$ have measured the argon mass spectrum under very similar experimental conditions and a peak width value of $0.05 \mathrm{eV}$ was achieved for the $\mathrm{Ar}^{+}$ion. Because the broadening in argon can only be the result of thermal energy and instrumental broadening, this value represents a good estimation for the instrumental resolution.

The HeI PE spectrum of $\mathrm{CH}_{2} \mathrm{CISCN}$ was recorded on a double-chamber UPS-II machine built specifically to detect transient species at a resolution of about $30 \mathrm{meV}$, as indicated by the $\operatorname{Ar}^{+}\left({ }^{2} \mathrm{P}_{3 / 2}\right)$ photoelectron band. ${ }^{36-39}$ Experimental vertical ionization energies $\left(I_{\mathrm{v}}\right.$ in $\left.\mathrm{eV}\right)$ were calibrated by simultaneous addition of a small amount of argon and iodomethane to the sample.

$\mathrm{OVGF}^{40}$ calculations using the cc-pVTZ basis set and MP2/ cc-pVTZ optimized geometry of gauche and anti forms of $\mathrm{CH}_{2} \mathrm{ClSCN}$ have been performed using the Gaussian 03 program package. ${ }^{41}$ Similarly, the symmetry adapted cluster/configuration interaction (SAC-CI) by Nakatsuji et al. ${ }^{42}$ was also applied for determine the ionization energies for both conformers.

The sample of $\mathrm{CH}_{2} \mathrm{ClSCN}$ was obtained from commercial sources (Aldrich, estimated purity better than 97\%). The liquid sample was purified by repeated trap-to-trap vacuum distillation. The purity of the compound in both vapor and liquid phases was checked by IR and ${ }^{1} \mathrm{H}$ NMR spectroscopies, respectively.

\section{RESULTS AND DISCUSSION}

Gas Phase Molecular Structure. Ionization energies in the valence region are known to be strongly dependent upon the molecular conformation. ${ }^{43}$ Very recently, Morini et al. ${ }^{44}$ showed that the inclusion of several conformers of $n$-hexane is needed for the accurate interpretation of the photoelectron and electron momentum spectra. To the best of our knowledge, for the title 
Table 1. Calculated Relative Energies for Stable Conformers of $\mathrm{CClH}_{2} \mathrm{SCN}$ in the Ground (in $\mathrm{kcal} \mathrm{mol}^{-1}$ ) and Low-Lying Radical Cationic (in eV) Electronic States

\begin{tabular}{|c|c|c|c|c|}
\hline & \multicolumn{2}{|c|}{$\mathrm{CClH}_{2} \mathrm{SCN}(\mathrm{kcal} / \mathrm{mol})$} & \multicolumn{2}{|c|}{$\mathrm{CClH}_{2} \mathrm{SCN}^{\bullet+}(\mathrm{eV})^{e}$} \\
\hline & gauche & trans & gauche $\left({ }^{2} \mathrm{~A}\right)$ & $\operatorname{trans}\left({ }^{2} A^{\prime \prime}\right)$ \\
\hline $\mathrm{MP} 2 / 6-311++\mathrm{G}^{* *}$ & $0.00^{a}$ & 1.52 & $10.80 / 10.23$ & $10.82 / 10.39$ \\
\hline $\mathrm{MP} 2 / 6-311++\mathrm{G}(3 \mathrm{df}, 2 \mathrm{p})$ & $0.00^{b}$ & 1.00 & $10.90 / 10.54$ & $10.98 / 10.53$ \\
\hline $\mathrm{MP} 2 / \mathrm{cc}-\mathrm{pVTZ}$ & $0.00^{c}$ & 0.81 & $10.94 / 10.52$ & $11.01 / 10.51$ \\
\hline$(\mathrm{U}) \operatorname{CCSD}(\mathrm{T}) / 6-311++\mathrm{G}^{* *}$ & $0.00^{d}$ & 1.45 & 10.34 & 10.43 \\
\hline
\end{tabular}

${ }^{a} E^{0}=-989.075445$ hartree. ${ }^{b} E^{0}=-989.250237$ hartree. ${ }^{c} E^{0}=-989.264020$ hartree. ${ }^{d} E=-989.1450235$ hartree. ${ }^{e}$ Møller-Plesset perturbation theory of the second order energy values under the spin-unrestricted (UMP2) and spin-restricted open-shell (ROMP2) approaches are given: UMP2/ ROMP2.

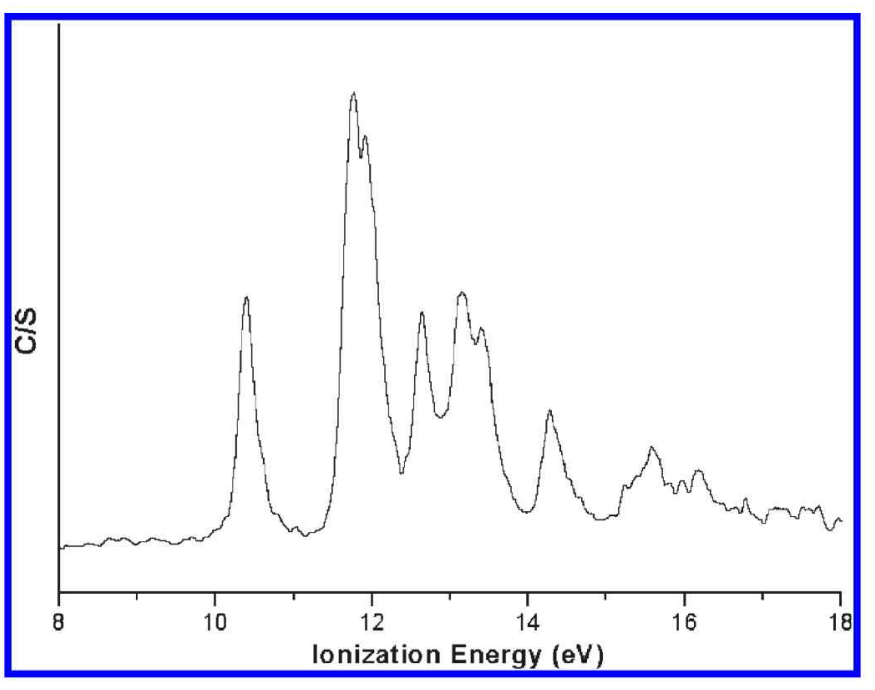

Figure 2. HeI photoelectron spectrum of $\mathrm{CH}_{2} \mathrm{ClSCN}$.

species, the only reference to this property is the work by Crowder $^{10,11}$ where the infrared and Raman spectra are interpreted supposing that the trans $C_{s}$ conformer is present in the liquid at room temperature (chlorine atom and SCN group in a mutual trans orientation). On the other hand, very recently the $\mathrm{X}$-ray crystal structure of $\mathrm{CH}_{2} \mathrm{ClSCN}$ at low temperature was determined ${ }^{45}$ by using the well established in situ crystallization technique. ${ }^{46}$ The molecular structure shows a gauche conformation between the $\mathrm{Cl}$ atom and the $-\mathrm{SCN}$ group, with a dihedral angle $\delta(\mathrm{ClC}-\mathrm{SC})=63.7(1)^{\circ}$. Thus, it is likely that the aggregation state strongly influence the most stable conformation of $\mathrm{CH}_{2} \mathrm{ClSCN}$. In absence of experimental studies for the gas phase molecular structure for this species, we decide to perform theoretical calculations to obtain a more detailed description of the molecular structure. The potential energy curve for small variation of the $\delta(\mathrm{ClC}-\mathrm{SC})$ dihedral angle was obtained at the $\operatorname{CCSD}(\mathrm{T}) /$ $6-311++G^{* *}$ (see Figure 1). The most stable conformation in the ground electronic state is the gauche conformer, the trans form lying in a flat minimum ca. $1.5 \mathrm{kcal} / \mathrm{mol}$ above the gauche conformer.

Full geometry optimizations and frequency calculations were performed for both conformers with the second-order perturbation theory methods and the $6-311++\mathrm{G}^{* *}, 6-311++\mathrm{G}(3 \mathrm{df}, 2 \mathrm{p})$, and cc-pVTZ basis sets (see Table 1). By taking into consideration the computed $\Delta G^{\circ}$ value at the MP2/cc-pVTZ level of approximation and degeneracy values ( $m$ is equal to 2 and 1 for the gauche and anti forms, respectively) from the Boltzmann distribution, a relative abundance of $38 \%$ of the less stable anti form is expected at $298 \mathrm{~K}$.
Table 2. Experimental and Calculated Ionization Energies (eV) and MO Characters for $\mathrm{CH}_{2} \mathrm{CISCN}$

\begin{tabular}{|c|c|c|c|c|c|c|}
\hline \multirow[b]{3}{*}{ exptl } & \multicolumn{4}{|c|}{ calculated } & \multirow[b]{3}{*}{ MO } & \multirow[b]{3}{*}{ characters } \\
\hline & \multicolumn{2}{|c|}{$\begin{array}{l}\text { SAC-CI/ } \\
\text { cc-pVTZ }\end{array}$} & \multicolumn{2}{|c|}{$\begin{array}{c}\text { OVGF/ } \\
\text { cc-pVTZ }^{a, b}\end{array}$} & & \\
\hline & gauche & anti & gauche & anti & & \\
\hline 10.39 & 10.28 & 10.34 & $10.24(0.91)$ & $10.22(0.91)\left(a^{\prime \prime}\right)$ & (27) & $\mathrm{n}_{\pi}(\mathrm{S})$ \\
\hline 11.72 & 11.53 & 11.87 & $11.60(0.90)$ & $11.76(0.90)\left(a^{\prime \prime}\right)$ & (26) & $\mathrm{n}_{\pi}(\mathrm{Cl})$ \\
\hline 11.93 & 11.85 & 12.14 & $11.91(0.91)$ & $12.15(0.91)\left(\mathrm{a}^{\prime}\right)$ & (25) & $\mathrm{n}_{\sigma}(\mathrm{Cl})$ \\
\hline 12.60 & 12.55 & 12.77 & $12.48(0.90)$ & $12.63(0.90)\left(a^{\prime \prime}\right)$ & (24) & $\pi_{2}(\mathrm{CN})$ \\
\hline 13.21 & 13.10 & 13.31 & $13.38(0.89)$ & $13.43(0.89)\left(a^{\prime}\right)$ & (23) & $\pi_{1}(\mathrm{CN})$ \\
\hline 13.45 & 13.49 & 13.59 & $13.61(0.93)$ & $13.62(0.90)\left(\mathrm{a}^{\prime}\right)$ & (22) & $\sigma(\mathrm{CN})$ \\
\hline 14.26 & 14.49 & 14.64 & $14.30(0.92)$ & $14.45(0.90)\left(a^{\prime}\right)$ & (21) & $\sigma(\mathrm{CH})$ \\
\hline 15.58 & 15.81 & 15.54 & $15.72(0.90)$ & $15.20(0.90)\left(\mathrm{a}^{\prime}\right)$ & (20) & \\
\hline
\end{tabular}

${ }^{a}$ Geometry computed at the MP2/cc-pVTZ level of approximation.

${ }^{b}$ Pole strength in parentheses.

Photoelectron Spectra. The most stable gauche form belongs to the $C_{1}$ point group while the anti form belongs to the $C_{s}$ symmetry point group. For the later, all canonical molecular orbitals of type $a^{\prime}$ are $\sigma$ orbitals lying in the molecular plane, while those of type a" are $\pi$ orbitals. Their 28 valence electrons are arranged in 14 doubly occupied orbital in the independent particle description. The PE spectrum of $\mathrm{CH}_{2} \mathrm{ClSCN}$ has been previously recorded by Mölder et al. ${ }^{47}$ These authors assigned the spectrum on the basis of the CNDO/ 2 method of calculation assuming a $C_{s}$ symmetry point group for the molecule. Unfortunately, when comparing with recent analysis for related systems, like $\mathrm{CH}_{3} \mathrm{SCN},{ }^{48}$ conflicts with this assignment are apparent. Thus, we decide to remeasure the $\mathrm{HeI}$ photoelectron spectrum with improved resolution and to complement the band assignment with the assistance of the higher-level quantum chemical calculations based on the outer-valence Green's function (OVGF) and SAC-CI approximations, beyond that of a single determinant wave function. The HeI $\mathrm{PE}$ spectrum of $\mathrm{CH}_{2} \mathrm{ClSCN}$ is depicted in Figure 2. The experimental and theoretical ionization energies are listed in Table 2.

The computed ionization energies using the SAC-CI method are in very good agreement with the experimental results, with maximum deviations of $0.19 \mathrm{eV}$ for ionization energies below $14 \mathrm{eV}$. Assignments were made with reference to the results of the OVGF/cc-pVTZ calculations [with an optimized geometry for the gauche $\left(C_{1}\right)$ and anti $\left(C_{s}\right)$ conformers at the MP2/cc-pVTZ level of approximation]. In spite that the experimental resolution of the PES precludes the observation of minor differences arising 


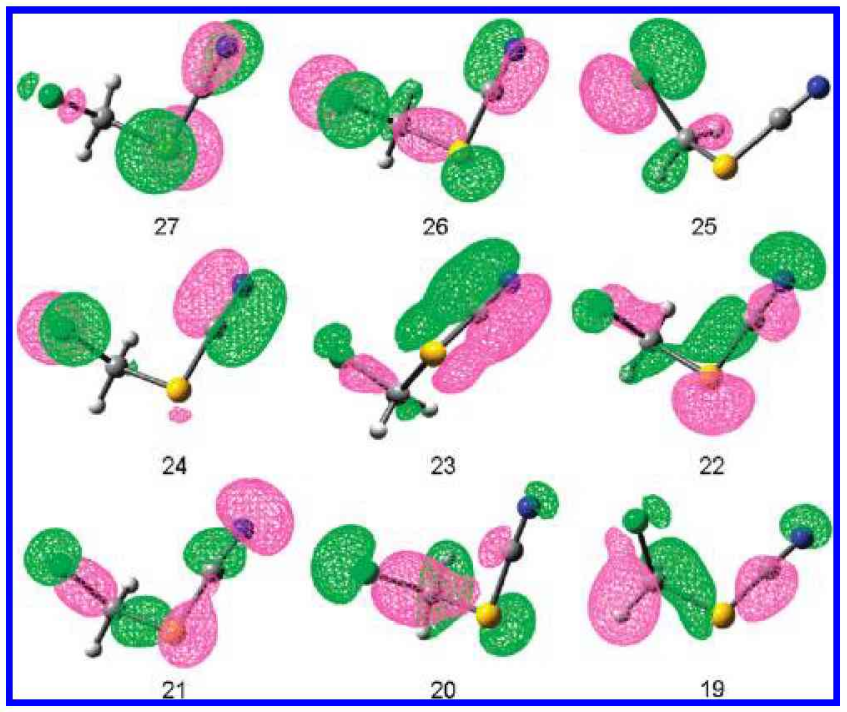

Figure 3. Characters of the eight highest occupied molecular orbitals of $\mathrm{CH}_{2} \mathrm{ClSCN}$.

from conformation-specificity, a better qualitative description is obtained when both conformers are considered. The characters of the eight highest occupied molecular orbitals of gauche $\mathrm{CH}_{2} \mathrm{ClSCN}$ are shown in Figure 3.

The first ionization band appearing in the spectrum at $10.39 \mathrm{eV}$ can be assigned with confidence to the ionization process from the HOMO, an $n_{\pi}(S)$ orbital, which can be visualized as a lone pair nominally localized on the sulfur atom. Due to resonance interactions, electron density contributions from the $\pi \mathrm{C} \equiv \mathrm{N}$ bond can be also postulated. Vertical ionization energies for the related species $\mathrm{CH}_{3} \mathrm{SCN}^{48} \mathrm{CCl}_{3} \mathrm{SCN}$, and $\mathrm{CCl}_{2} \mathrm{FSCN}$ are 10.13, 10.55, and $10.78 \mathrm{eV}$, respectively. ${ }^{49}$ Thus, the substitution of hydrogen in $\mathrm{CH}_{3} \mathrm{SCN}$ by fluorine or chlorine atoms increases the IP value, in accordance with the electron-withdrawing properties of halogens. A relation of this type can be expected because increase of the ionization potential means decrease of the negative charge attached to the sulfur atom due to the electronegativity of the halogens.

Other interesting feature associated with the first ionization potential of $\mathrm{CH}_{2} \mathrm{CISCN}$ is the observation that the band at $10.39 \mathrm{eV}$ is quite narrow and structureless. As early reported for sulfur-containing species, ${ }^{50}$ the photoelectron bands produced on ionization of a nonbonding electron is characteristically sharp reflecting the negligible change in the Franck-Condon envelope between neutral and ionic species. To better characterize the potential energy hypersurface of the low-lying cationic state, the calculated [UCCSD $\left.(\mathrm{T}) / 6-311++\mathrm{G}^{* *}\right]$ potential energy curve obtained by varying the $\delta(\mathrm{ClC}-\mathrm{SC})$ dihedral angle is also shown in Figure 1. The most stable gauche conformation is retained upon ionization, with minor variation in the $\delta(\mathrm{ClC}-\mathrm{SC})$ dihedral angle values. In effect, the minimum corresponding to the gauche forms is slightly shifted to higher dihedral angles in the cationic form, amounting $70.5^{\circ}$ and $84.3^{\circ}$ for the neutral and low-lying cationic forms, respectively, as computed at the (U)MP2/cc-pVTZ level of approximation. On this basis, similar vertical and adiabatic ionization energies can be anticipated for the title species. As showed in Table 1 and Figure 1, the computed UCCSD(T) $/ 6-311++\mathrm{G}^{* *}$ value is $10.34 \mathrm{eV}$, whereas the UMP2 method yield adiabatic ionization energies which are too high (ca. $10.90 \mathrm{eV}$ ) when compared with the experimental photoelectron spectra, even when extensive basis sets are used.

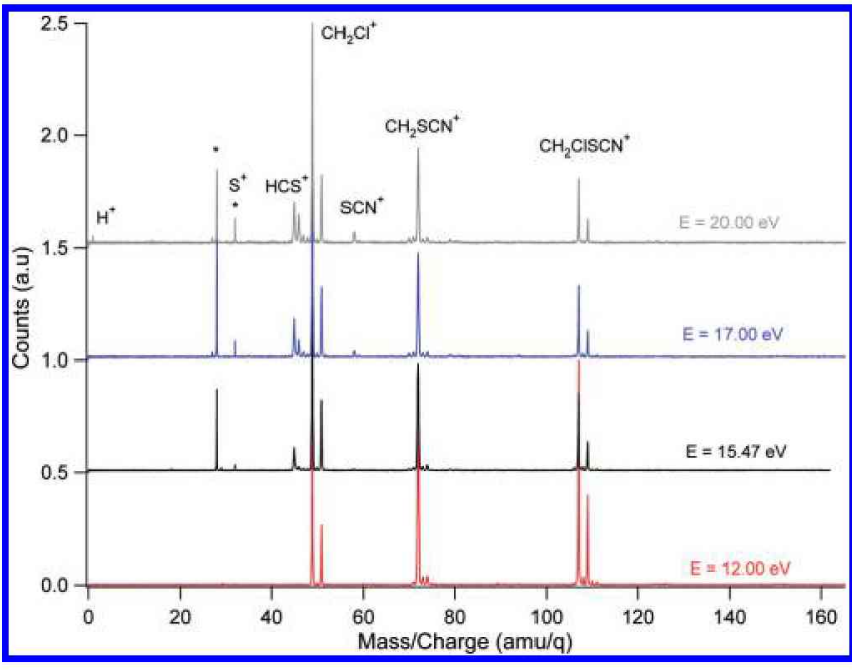

Figure 4. PEPICO spectra of $\mathrm{CH}_{2} \mathrm{ClSCN}$ at selected photon energies in the valence region. Bands marked with asterisks $\left({ }^{*}\right)$ maybe originated by traces of $\mathrm{N}_{2}^{+}$and $\mathrm{O}_{2}^{+}$.

It is worthy to mention that moderate spin contaminations were computed for the UMP2 method, with $\left\langle S^{2}\right\rangle$ values of 0.88 and 0.92 , for the gauche and trans conformers, respectively (a pure spin doublet has an $\left\langle S^{2}\right\rangle$ values of 0.75 ). Thus, following HeadGordon and co-workers, ${ }^{51}$ the ROMP2 approximation was also applied. The computed adiabatic ionization potential values are listed in Table 1, showing a good agreement with the experimental available data and with the most reliable UCCSD $(T)$ method. Moreover, geometry optimization and frequency calculations were computed for both gauche $\left({ }^{2} \mathrm{~A}\right)$ and trans $\left({ }^{2} \mathrm{~A}^{\prime \prime}\right)$ conformers of $\mathrm{CH}_{2} \mathrm{ClSCN}^{+}$in the cationic state. These results demonstrate that Mulliken atomic charges are mainly localized in the $-\mathrm{SCN}$ group of $\mathrm{CH}_{2} \mathrm{ClSCN}^{*+}$ (Supporting Information, Table S1). The partial positive charge of the $S$ and $N$ are increased by 0.74 and 0.22 units upon ionization, respectively.

The second and third ionization potentials, observed at 11.72 and $11.93 \mathrm{eV}$, are assigned to the ionization processes of electrons ejected from nonbonding orbitals predominantly located at the chlorine atom. The following band, observed at $12.60 \mathrm{eV}$, is associated with ionizations from the $\pi$ system of the $\mathrm{S}-\mathrm{C} \equiv \mathrm{N}$ group. Following the early assignments of Cradock et al. ${ }^{52}$ for methyl pseudohalides, the splitting of the $n_{\pi}(S) / \pi_{2}$ components in the thiocyanate system is $2.21 \mathrm{eV}$, slightly higher than the parent $\mathrm{CH}_{3} \mathrm{SCN}$ species $(2.06 \mathrm{eV}){ }^{48}$ The splitting of the $\pi$ orbitals depends, to some extent, on the $\mathrm{C}-\mathrm{S}-\mathrm{C}$ bond angle: the splitting decreases when the bond angle approaches to $180^{\circ}$. For the title species, the experimental value for the $\mathrm{C}-\mathrm{S}-\mathrm{C}$ bond angle is $98.28(6)^{\circ},{ }^{45}$ similar to that found for other thiocyanates. This value can be also related with the $\mathrm{CN}$ bond length diminution when the ionization potential increases.

The three bands observed in the higher energy region are attributable to ionizations from the more inner-valence bonded orbitals, the $13.45 \mathrm{eV}$ signal originates from ionization from the $\sigma_{\mathrm{CN}}$, whereas the 14.26 and $15.58 \mathrm{eV}$ bands are assigned to $\sigma_{\mathrm{CH}}$ bonds in the $-\mathrm{CH}_{2} \mathrm{Cl}$ group.

Finally, it is worthy to note that in one-particle Green's function calculations performed using a diagonal self-energy (quasiparticle approximation) such as OVGF, pole strengths larger than 0.80 are assumed to validate the one-electron picture of ionization. ${ }^{53}$ However, Deleuze and co-workers demonstrate 


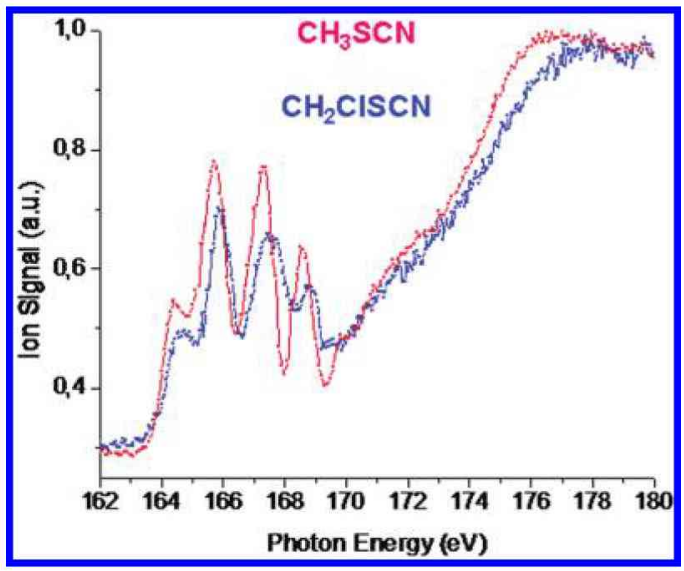

Figure 5. Total ion yield spectrum for $\mathrm{CH}_{2} \mathrm{ClSCN}$ (blue trace) and $\mathrm{CH}_{3} \mathrm{SCN}^{22}$ (red trace) near the S $2 \mathrm{p}$ edge.

that pole strengths smaller than 0.85 systematically corroborate a breakdown of the orbital picture of ionization, ${ }^{54}$ compared with the results of more reliable $\mathrm{ADC}(3)$ calculations coping properly with configuration interactions in the final state. For the title species, despite the limitations of the cc-pVTZ basis set, the computed OVGF predict pole strengths values typically around 0.90 and the one-electron ionization spectra is in good agreement with the available $\mathrm{He}(\mathrm{I})$ photoelectron spectra, up to binding energies of ca. $15.50 \mathrm{eV}$.

Photoionization in the Valence Region. The TOF-mass spectra for $\mathrm{CH}_{2} \mathrm{ClSCN}$ irradiated with photons with energy in the $12.0-20.0 \mathrm{eV}$ range is shown in the Figure 4. When photon with $12.0 \mathrm{eV}$ are used (the lower energy delivered by the TGM line) a very simple spectrum is obtained, with the presence of signal clearly assigned to the molecular ion at $107 \mathrm{amu} / \mathrm{q}$ and fragment ions at 72 and $49 \mathrm{amu} / \mathrm{q}$ due to the $\mathrm{CH}_{2} \mathrm{SCN}^{+}$and $\mathrm{CH}_{2} \mathrm{Cl}^{+}$ions. Naturally occurring isotopic contributions are plainly resolved, giving confidence to this assignment. The fragmentation pattern is quite similar for all the photon energies here investigated, with minor contribution of the $\mathrm{HCS}^{+}$and $\mathrm{SCN}^{+}$ions at higher photon energies. The signals observed at times corresponding to the arrive of ions with a $m / z=28$ and 32 are probably due to contribution of air in the sample or nondetected vacuum leaks. These signals do not appear at $12.0 \mathrm{eV}$ since this energy does not reach to ionize either nitrogen or oxygen molecules.

The single charged molecular ion is observed in the whole range of photon energies studied. A clear diminution of the peak intensity for $\mathrm{CH}_{2} \mathrm{ClSCN}^{+}$ion is observed when the photon energy is augmented and higher excited cationic state are populated. When the sample is irradiated with $12.0 \mathrm{eV}$ photons, a few cationic states can be reached. Following the assignment proposed in Table 2, lone pair electrons nominally from the sulfur and chlorine can be ionized. The ionic dissociation in this region can be qualitatively understood in terms of the cationic states reached after photon absorption. Thus, the rupture of the sulfur-carbon single bond in $\mathrm{CH}_{2} \mathrm{ClSCN}^{+}$ can be observed, probably from the low-lying ${ }^{2} \mathrm{~A}^{\prime \prime}$ cationic state. The fragmentation leads exclusively to the formation of the $\mathrm{CH}_{2} \mathrm{Cl}^{+}$ion, with only minor amounts of $\mathrm{SCN}^{+}$at photon energies higher than 17.0 eV. The following mechanisms can be proposed:

$$
\mathrm{CH}_{2} \mathrm{ClSCN}^{+} \rightarrow \mathrm{CH}_{2} \mathrm{Cl}^{+}+\mathrm{SCN}
$$

It is reasonable that the ionization of chlorine lone pair electrons affect the electron distribution around the chloromethyl

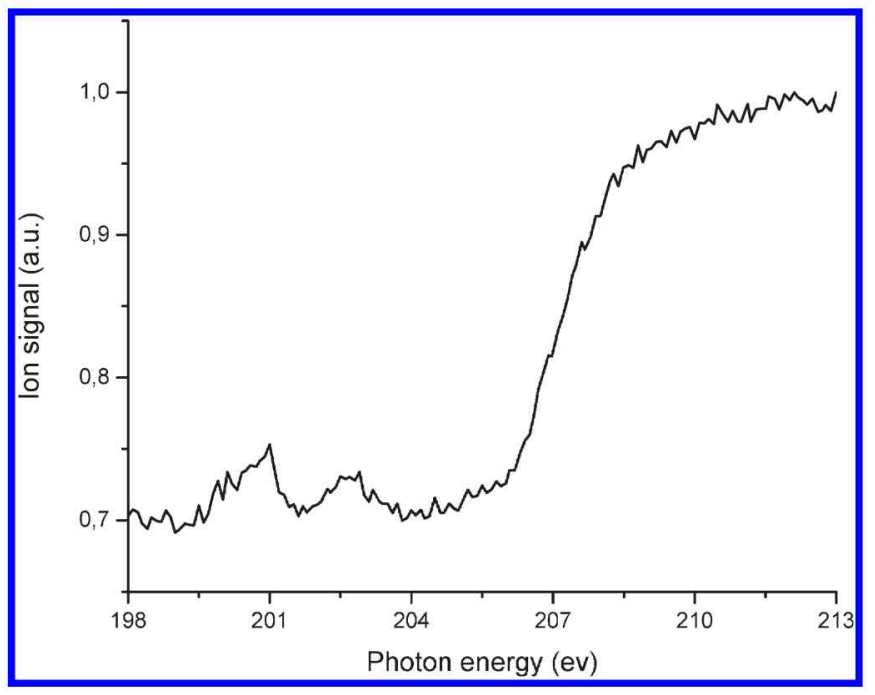

Figure 6. Total ion yield spectrum for $\mathrm{CH}_{2} \mathrm{ClSCN}$ near the $\mathrm{Cl} 2 \mathrm{p}$ edge.

Table 3. Transition Energies (eV) and Proposed Assignments for Features in the Photon (TIY) Excited Spectra of $\mathrm{CH}_{2} \mathrm{ClSCN}$ at the $\mathrm{S} 2 \mathrm{p}$ and $\mathrm{Cl} 2 \mathrm{p}$ Levels $^{a}$

\begin{tabular}{|c|c|c|c|}
\hline \multirow[b]{2}{*}{$\mathrm{CH}_{2} \mathrm{CISCN}$} & \multicolumn{2}{|c|}{$\mathrm{CH}_{3} \mathrm{SCN}$} & \multirow[b]{2}{*}{ proposed assignment $^{21}$} \\
\hline & $\mathrm{TIY}^{22}$ & ISEELS $^{21}$ & \\
\hline 164.7 & 164.4 & $165.0 \mathrm{sh}$ & $\pi_{1}^{*}{ }_{\mathrm{SCN}}\left(\mathrm{S} 2 \mathrm{p}_{3 / 2}\right)$ \\
\hline 165.9 & 165.7 & 165.9 & $\pi_{1}^{*}{ }_{\mathrm{SCN}}\left(\mathrm{S} 2 \mathrm{p}_{3 / 2}\right)+\pi_{2}^{*}{ }_{\mathrm{SCN}}\left(\mathrm{S} 2 \mathrm{p}_{1 / 2}\right)$ \\
\hline 167.6 & 167.2 & 167.5 & $\sigma_{C S}^{*}\left(S 2 p_{3 / 2}\right)+\pi_{2}^{*}{ }_{S C N}\left(S 2 p_{1 / 2}\right)$ \\
\hline 168.9 & 168.5 & 168.7 & $\sigma_{C S}^{*}\left(S 2 p_{1 / 2}\right)$ \\
\hline 169.5 & 170.0 & $170.3 \mathrm{sh}$ & Ryd/continuum onset $\left(\mathrm{S} 2 \mathrm{p}_{3 / 2}\right)$ \\
\hline 177.0 & 176.7 & 176.9 & $2 p$ continuum delayed maximum $\left(S 2 p_{3 / 2}\right)$ \\
\hline 200.7 & & & $\sigma_{\mathrm{Cl}-\mathrm{C}}^{*}\left(\mathrm{Cl} 2 \mathrm{p}_{3 / 2}\right)$ \\
\hline 202.8 & & & $\sigma_{\mathrm{Cl}-\mathrm{C}}^{*}\left(\mathrm{Cl} 2 \mathrm{p}_{1 / 2}\right)$ \\
\hline 208.9 & & & continuum onset $\left(\mathrm{Cl} 2 \mathrm{p}_{3 / 2}\right)$ \\
\hline
\end{tabular}

group. Following this idea, the $\mathrm{CH}_{2} \mathrm{SCN}^{+}$ion can be characterized as formed from the parent ion by rupture of the $\mathrm{C}-\mathrm{Cl}$ bond, the charge retained in the molecular fragment:

$$
\mathrm{CH}_{2} \mathrm{ClSCN}^{\bullet+} \rightarrow \mathrm{CH}_{2} \mathrm{SCN}^{+}+\mathrm{Cl}^{\bullet}
$$

The $70 \mathrm{eV}$ electron impact mass spectrum of $\mathrm{CH}_{2} \mathrm{CISCN}$ is available rom the $\mathrm{Web}^{55}$ and can serve for comparison with our results. Indeed, the photon- and electron impact spectra are very similar: the $\mathrm{CH}_{2} \mathrm{Cl}^{+}$ion is the most abundant one, with intense signals for the molecular $\left(\mathbf{M}^{+}\right)$and the $m / z=72(\mathbf{M}-35)$ ions. In the electron impact spectrum the $\mathrm{HCS}^{+}$and $\mathrm{SCN}^{+}$ions are also observed with minor abundance, amounting ca. 7 and $3 \%$ of the formed ions, respectively.

Total Ion Yield Spectra (TIY). The TIY spectra were obtained by recording the count rates of the total ions while the photon energy is scanned. At high photon energies the detection of the parent and fragment ions as a function of the incident photon energy is a powerful method to be used as a complement to the absorption spectroscopy. ${ }^{56}$ The TIY spectrum of $\mathrm{CH}_{2} \mathrm{CISCN}$, measured near the $\mathrm{S} 2 \mathrm{p}$ edge is shown in Figure 5. For comparison, the spectrum of $\mathrm{CH}_{3} \mathrm{SCN}^{22}$ in the same region is also presented, the similarity between the spectra is evident. 


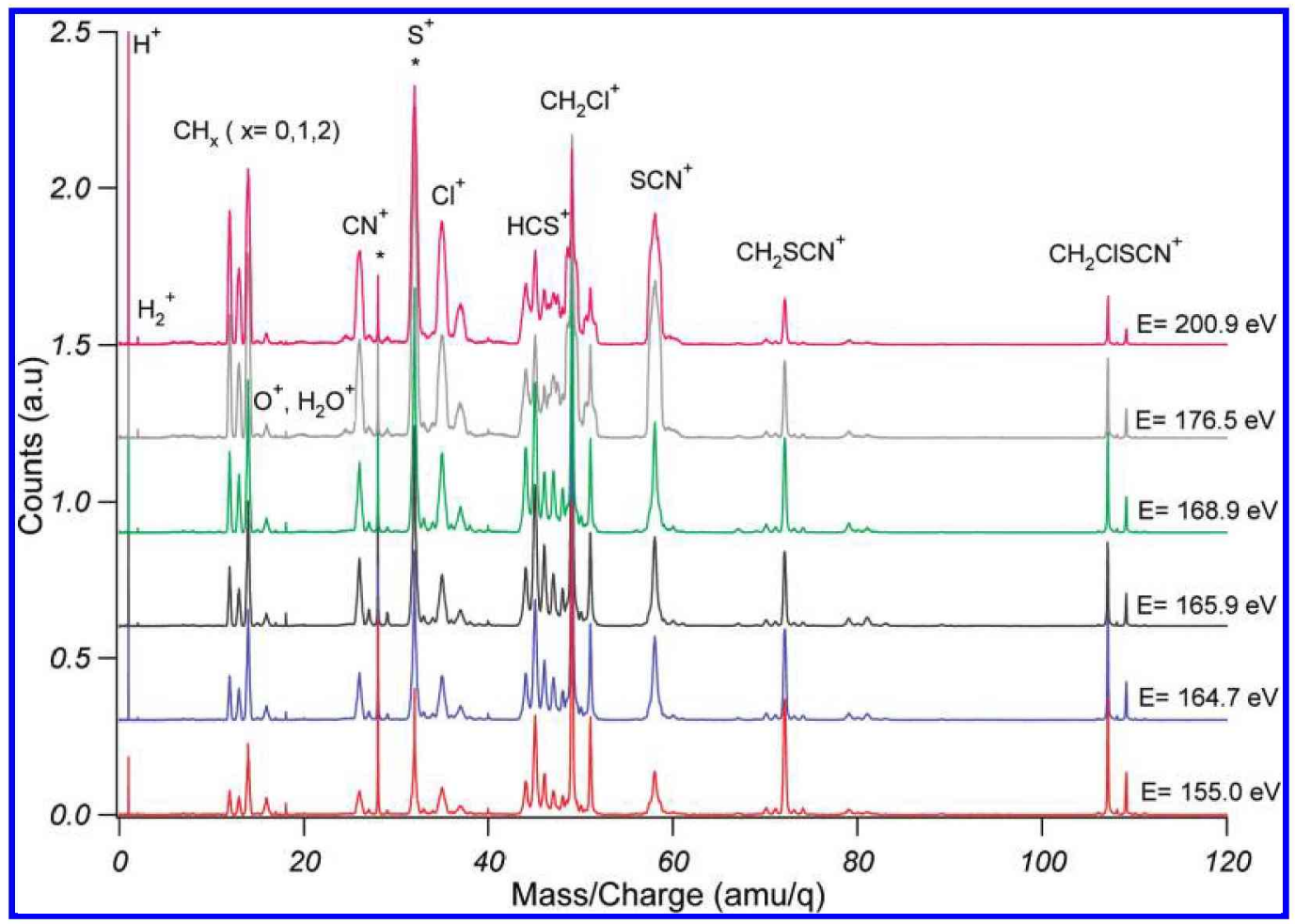

Figure 7. PEPICO spectra of $\mathrm{CH}_{2} \mathrm{ClSCN}$ at selected energies near the $\mathrm{S} 2 \mathrm{p}$ and $\mathrm{Cl} 2 \mathrm{p}$ edges. Bands marked with asterisks $\left(^{*}\right)$ maybe originated by traces of $\mathrm{N}_{2}^{+}$and $\mathrm{O}_{2}^{+}$.

Table 4. Branching ratios (\%) for fragment ions extracted from PEPICO spectra taken at photon energies around the $S 2 \mathrm{p}$ edge for $\mathrm{CH}_{2} \mathrm{ClSCN}$. Kinetic energy release values (in eV) determined from the spectra at 165.9 and $200.9 \mathrm{eV}$ are given in italics

\begin{tabular}{|c|c|c|c|c|c|c|c|c|c|c|}
\hline \multirow[b]{2}{*}{$m / z$} & \multirow[b]{2}{*}{ ion $^{a}$} & \multicolumn{9}{|c|}{ photon energy $(\mathrm{eV})$} \\
\hline & & 155.0 & 164.7 & 165.9 & 167.6 & 168.9 & 176.5 & 200.9 & 202.7 & 250.0 \\
\hline 1 & $\mathrm{H}^{+}$ & 2.72 & 3.03 & $3.10 / 3.83$ & 3.86 & 4.27 & 4.90 & $7.15 / 6.48$ & 7.44 & 9.78 \\
\hline 2 & $\mathrm{H}_{2}^{+}$ & 0.11 & 0.12 & 0.14 & 0.14 & 0.14 & 0.18 & & 0.29 & 0.28 \\
\hline 12 & $\mathrm{C}^{+}$ & 2.28 & 2.98 & $3.34 / 2.44$ & 3.94 & 4.05 & 4.40 & $6.52 / 3.92$ & 6.72 & 8.25 \\
\hline 13 & $\mathrm{CH}^{+}$ & 1.84 & 2.40 & $2.45 / 3.00$ & 3.04 & 3.29 & 3.26 & $4.49 / 5.88$ & 4.62 & 5.10 \\
\hline 14 & $\mathrm{CH}_{2}^{+} / \mathrm{N}^{+}$ & 6.87 & 7.72 & $7.39 / 2.63$ & 7.91 & 7.86 & 8.38 & $10.6 / 5.86$ & 10.8 & 11.9 \\
\hline 16 & $\mathrm{O}^{+}$ & 2.15 & 1.34 & $1.06 / 3.69$ & 0.974 & 1.05 & 0.654 & & & \\
\hline 26 & $\mathrm{CN}^{+}$ & 3.01 & 3.94 & $4.62 / 1.64$ & 4.64 & 4.43 & 5.04 & $6.67 / 3.87$ & 6.74 & 8.00 \\
\hline 27 & $\mathrm{HCN}^{+}$ & 0.481 & 0.576 & $0.89 / 0.47$ & 0.548 & 0.544 & 0.526 & & & \\
\hline $32^{*}$ & $s^{+}$ & 7.28 & 9.89 & $9.99 / 0.82$ & 10.8 & 11.0 & 12.5 & $15.9 / 2.32$ & 15.9 & 15.9 \\
\hline 35 & $\mathrm{Cl}^{+}$ & 5.30 & 5.81 & $5.83 / 1.85$ & 7.49 & 7.73 & 8.09 & $12.75 / 2.99$ & 12.48 & 19.16 \\
\hline 44 & $\mathrm{CS}^{+}$ & 3.13 & 3.23 & $3.52 / 0.70$ & 4.28 & 4.30 & 2.89 & $3.76 / 2.85$ & 3.81 & \\
\hline 45 & $\mathrm{HCS}^{+}$ & 7.86 & 7.25 & $7.61 / 0.40$ & 7.89 & 7.07 & 3.43 & $4.04 / 0.37$ & 3.73 & \\
\hline 46 & $\mathrm{H}_{2} \mathrm{CS}^{+}$ & 3.26 & 3.55 & $4.05 / 0.29$ & 3.49 & 2.83 & 2.00 & 2.16 & 1.42 & \\
\hline 47 & $\mathrm{CCl}^{+}$ & 1.99 & 2.52 & $2.60 / 0.21$ & 2.54 & 2.65 & 2.50 & & & \\
\hline 48 & $\mathrm{CHCl}^{+}$ & 1.24 & 1.44 & $1.50 / 0.12$ & 1.49 & 1.57 & 1.32 & & & \\
\hline 49 & $\mathrm{CH}_{2} \mathrm{Cl}^{+}$ & 19.14 & 16.05 & $14.34 / 0.09$ & 12.54 & 12.18 & 13.33 & 13.91 & 13.67 & 10.11 \\
\hline 58 & $\mathrm{SCN}^{+}$ & 5.10 & 6.25 & $5.50 / 0.41$ & 5.44 & 5.88 & 9.62 & $10.1 / 2.54$ & 10.2 & 8.78 \\
\hline 72 & $\mathrm{CH}_{2} \mathrm{SCN}^{+}$ & 5.75 & 3.33 & $2.30 / 0.06$ & 2.30 & 2.57 & 1.28 & $1.01 / 0.07$ & 1.01 & 1.47 \\
\hline 89 & $\mathrm{ClCs}^{+}$ & 0.78 & 0.83 & 0.94 & 0.74 & 0.64 & 0.47 & & & \\
\hline 107 & $\mathrm{CH}_{2} \mathrm{ClSCN}^{+}$ & 3.27 & 2.11 & 1.52 & 1.42 & 1.55 & 0.75 & 0.38 & 0.43 & 0.19 \\
\hline
\end{tabular}

Below the S 2 p threshold, the spectrum for the title species is dominated by a group of well-defined signals centered at 164.7 ,
$165.9,167.6$, and $168.9 \mathrm{eV}$. These resonant transitions should correspond to dipole allowed transitions that involve excitations 
of a $2 p$ electron to an antibonding molecular orbital. Following the proposed assignment for $\mathrm{S} 2 \mathrm{p}$ transitions for $\mathrm{CH}_{3} \mathrm{SCN}^{21}$ the main features have been assigned to states associated with $\left(\mathrm{S} 2 \mathrm{p}, \pi_{\mathrm{SCN}}^{*}\right)$ and $\left(\mathrm{S} 2 \mathrm{p}, \sigma_{\mathrm{CS}}^{*}\right)$ configurations. In particular, the well resolved structures observed in the TIY spectrum of $\mathrm{CH}_{2} \mathrm{CISCN}$ can be interpreted as originated by electronic transitions involving the spin-orbit split of the $2 p$ sulfur excited species $\left(2 \mathrm{p}_{1 / 2}\right.$ and $2 \mathrm{p}_{3 / 2}$ levels) to unoccupied antibonding orbitals, mainly the LUMO $\pi_{\mathrm{SCN}}^{*}\left(\mathrm{a}^{\prime}\right.$ and $\left.\mathrm{a}^{\prime \prime}\right)$ and $\sigma_{\mathrm{C}-\mathrm{S}}^{*}$ orbitals. Quantum chemical calculations at the MP2/6-311++G(3df) level of approximation for neutral $\mathrm{CH}_{2} \mathrm{ClSCN}$ in its ground state predict an unoccupied orbital arrangement which is in agreement with this description (see Figure S1 in the Supporting Information).

The TIY spectrum measured near the $\mathrm{Cl} 2 \mathrm{p}$ region is shown in Figure 6. The $\mathrm{Cl} 2 \mathrm{p}$ threshold is located at approximately $208.9 \mathrm{eV}$, and only two broad and poor-resolved signals can be observed at 200.7 and $202.8 \mathrm{eV}$. By comparison with previous studies on chlorinated species, ${ }^{57}$ these signals could be assigned to unresolved transitions involving the spin-orbital split of the $2 p$ term in the $2 p_{1 / 2}$ and $2 p_{3 / 2}$ levels of the excited species toward the LUMO $+2\left(\sigma^{*} \mathrm{Cl}-\mathrm{C}\right)$ vacant orbital. ${ }^{58}$ These results are summarized in Table 3.

PEPICO Spectra. PEPICO spectra have been recorded by setting the photon energy at the resonant values observed in the TIY spectrum. In order to identify the role of resonant processes in the fragmentation, the spectra were also measured at photon energy values below (typically $10 \mathrm{eV}$ ) and above (typically $50 \mathrm{eV}$ ) the ionization edge. The PEPICO spectra near the $S 2 p$ and $\mathrm{Cl} 2 \mathrm{p}$ edges are shown in Figure 7 and the branching ratios are given in Table 4.

When $\mathrm{CH}_{2} \mathrm{ClSCN}$ is irradiated with $155.0 \mathrm{eV}$ photons in the valence continuum region of the spectrum, the $\mathrm{CH}_{2} \mathrm{Cl}^{+}$ion is mainly formed, with a relative abundance of ca. $19 \%$. The $\mathrm{SCN}^{+}$ ion is also present with an intensity of $5.1 \%$. Other intense peaks observed in the PEPICO spectra correspond to the $\mathrm{S}^{+}, \mathrm{Cl}^{+}$, and $\mathrm{HCS}^{+}$ions, with relative abundances of $7.3,5.3$, and $7.8 \%$, respectively. The $\mathrm{HCS}^{+}$ion has been also constantly observed in the ionic fragmentation of other sulfur-compound having a methyl group such as $\mathrm{ClC}(\mathrm{O}) \mathrm{SCH}_{3},{ }^{59} \mathrm{CH}_{3} \mathrm{SCN}^{22}$ and specially $\mathrm{FC}(\mathrm{O}) \mathrm{SCH}_{3}{ }^{60}$ It is worth noting also that the thioformyl ion is fairly abundant in the interstellar medium and, in fact, was observed by Thaddeus et al. in $1981^{61}$ before it was studied in the laboratory by Gudeman et al. ${ }^{62}$ and later by Bogey et al. ${ }^{63}$ Mainly because of its low recombination energy (charge transfer reactions are inhibited therefore) and the relatively large proton affinity of $\mathrm{CS}^{64}$ which inhibits proton transfer from $\mathrm{HCS}^{+}$to most molecular species, $\mathrm{HCS}^{+}$is unreactive with all of the most abundant interstellar molecules and this is an important reason why it is readily detectable in interstellar clouds. $^{65}$

The kinetic energy release values have been determined for each ion. In Table 4 the values obtained for two characteristic photon energies are given, i.e., 165.9 and $200.9 \mathrm{eV}$ in the $\mathrm{S} 2 \mathrm{p}$ and $\mathrm{Cl} 2 \mathrm{p}$ regions, respectively. In the former spectrum, the ions show KER values which are lower than the later, a broadening in the peak widths are clearly observed when higher photon energies are used, favoring normal Auger decay processes.

Figure 8 shows the PEPICO spectra for arriving times corresponding to the $\mathrm{CH}_{2} \mathrm{Cl}^{+}$ion. From the peak shape observed at $200.9 \mathrm{eV}$ in the $\mathrm{Cl} 2 \mathrm{p}$ region, a clear double KER distribution can be recognized. This behavior could be rationalized in the case that this ion is generated from both, single and double charged

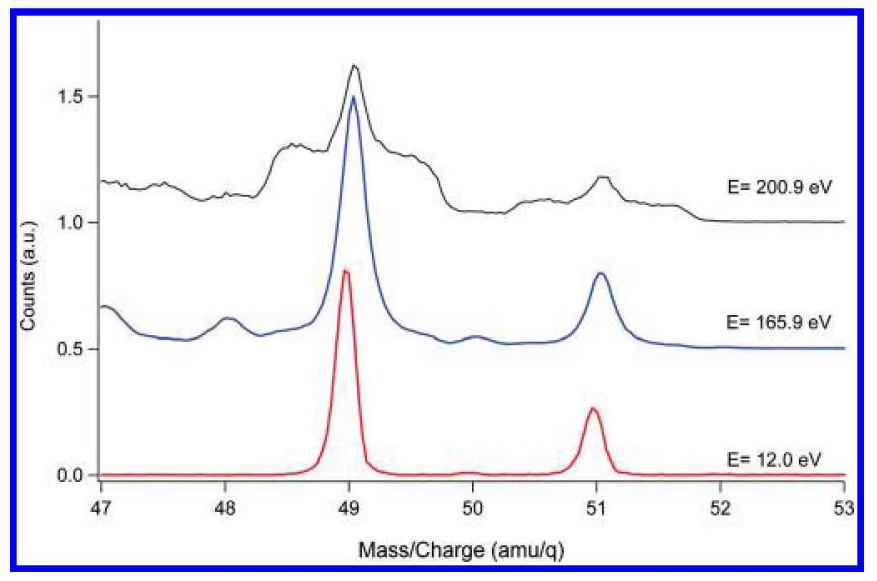

Figure 8. Enlargement of the $48-52 \mathrm{amu} / \mathrm{q}$ region of the PEPICO spectra of $\mathrm{CH}_{2} \mathrm{ClSCN}$ at selected photon energies.

Table 5. Relative Intensities for Double Coincidence Islands Derived from the PEPIPICO Spectra of $\mathrm{CH}_{2} \mathrm{CISCN}$ as a Function of the Photon Energy

\begin{tabular}{|c|c|c|c|c|c|c|c|}
\hline \multirow[b]{2}{*}{ ion 1} & \multirow[b]{2}{*}{ ion 2} & \multicolumn{4}{|c|}{$S 2 p$} & \multicolumn{2}{|c|}{$\mathrm{Cl} 2 \mathrm{p}$} \\
\hline & & 155.0 & 165.9 & 164.7 & 176.5 & 200.9 & 202.7 \\
\hline $\mathrm{CH}_{2}^{+}$ & $\mathrm{S}^{+}$ & 6.30 & 6.74 & 7.52 & 5.97 & 6.18 & 6.07 \\
\hline $\mathrm{CH}_{2} \mathrm{Cl}^{+}$ & $\mathrm{SCN}^{+}$ & 16.77 & 6.10 & 8.59 & 11.19 & 7.98 & 7.56 \\
\hline $\mathrm{s}^{+}$ & $\mathrm{CH}_{2} \mathrm{Cl}^{+}$ & 6.79 & 6.10 & 6.39 & 7.05 & 5.48 & 5.26 \\
\hline $\mathrm{C}^{+}$ & $\mathrm{S}^{+}$ & 2.84 & 4.00 & 4.12 & 3.27 & 4.15 & 4.20 \\
\hline $\mathrm{H}^{+}$ & $s^{+}$ & 5.44 & 3.90 & 4.53 & 3.8 & 4.63 & 4.69 \\
\hline$S^{+}$ & $\mathrm{Cl}^{+}$ & 3.29 & 3.70 & 3.85 & 4.29 & 4.21 & 4.31 \\
\hline $\mathrm{CN}^{+}$ & $\mathrm{s}^{+}$ & 1.74 & 3.30 & 3.11 & 3.00 & 3.55 & 3.60 \\
\hline $\mathrm{CH}_{2}^{+}$ & $\mathrm{Cl}^{+}$ & 2.79 & 2.91 & 3.08 & 3.29 & 3.59 & 3.62 \\
\hline $\mathrm{H}^{+}$ & $\mathrm{C}^{+}$ & 4.33 & 2.86 & 3.18 & 2.68 & 3.45 & 3.42 \\
\hline $\mathrm{CH}_{2}^{+}$ & $\mathrm{SCN}^{+}$ & 5.04 & 2.51 & 3.5 & 4.78 & 3.71 & 3.60 \\
\hline $\mathrm{CN}^{+}$ & $\mathrm{HCS}^{+}$ & 2.81 & 2.50 & 2.40 & 1.13 & & \\
\hline $\mathrm{H}^{+}$ & $\mathrm{Cl}^{+}$ & 3.28 & 2.45 & 2.82 & 2.40 & 3.03 & 3.07 \\
\hline $\mathrm{C}^{+}$ & $\mathrm{Cl}^{+}$ & 1.56 & 2.20 & 1.98 & 1.88 & 2.55 & 2.59 \\
\hline $\mathrm{C}^{+}$ & $\mathrm{N}^{+} / \mathrm{CH}_{2}^{+}$ & 1.02 & 2.07 & 1.77 & 1.52 & 1.97 & 2.00 \\
\hline$S^{+}$ & $\mathrm{CCl}^{+}$ & 1.71 & 2.03 & 2.00 & 2.12 & 1.80 & 1.82 \\
\hline $\mathrm{CH}_{2}^{+}$ & $\mathrm{SC}^{+}$ & 1.07 & 1.98 & & 1.51 & 1.58 & 1.59 \\
\hline $\mathrm{Cl}^{+}$ & $\mathrm{HCS}^{+}$ & 3.12 & 1.89 & 2.05 & 1.27 & 1.27 & 1.23 \\
\hline $\mathrm{CN}^{+}$ & $\mathrm{CH}_{2} \mathrm{Cl}^{+}$ & & 1.61 & & 1.31 & 1.06 & 1.11 \\
\hline $\mathrm{H}^{+}$ & $\mathrm{CS}^{+}$ & 2.77 & 1.60 & 1.96 & 1.15 & 1.32 & 1.31 \\
\hline $\mathrm{CN}^{+}$ & $\mathrm{Cl}^{+}$ & 1.04 & 1.54 & 1.33 & 1.18 & 1.47 & 1.51 \\
\hline $\mathrm{H}^{+}$ & $\mathrm{CN}^{+}$ & 1.83 & 1.52 & 1.59 & 1.31 & 1.57 & 1.56 \\
\hline $\mathrm{CH}_{2}^{+}$ & $\mathrm{CN}^{+}$ & & 1.48 & 1.36 & 1.26 & 1.27 & 1.28 \\
\hline
\end{tabular}

molecular ion according to the equations

$$
\begin{aligned}
& \mathrm{CH}_{2} \mathrm{ClSCN}^{+} \rightarrow \mathrm{CH}_{2} \mathrm{Cl}^{+}+\mathrm{SCN} \\
& \mathrm{CH}_{2} \mathrm{ClSCN}^{2+} \rightarrow \mathrm{CH}_{2} \mathrm{Cl}^{+}+\mathrm{SCN}^{+}
\end{aligned}
$$

Ions originated in the first process should have narrower KER distribution than those arising from the second. When the photon energy is increased and normal Auger decay prevails, the second dissociation channel is enhanced and broader peaks are observed. 


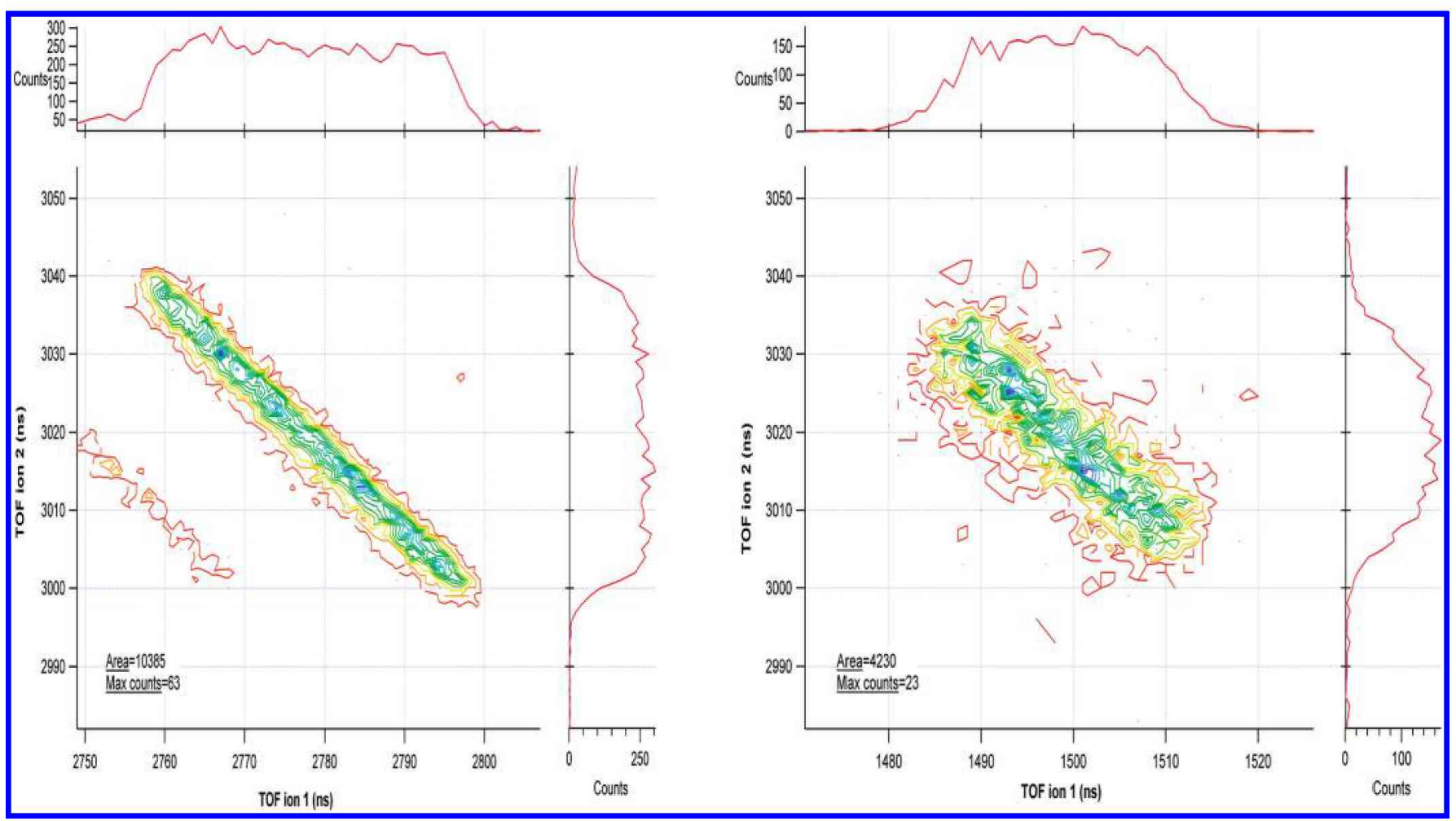

Figure 9. Contour plot for the coincidence island between ion pairs derived from $165.9 \mathrm{eV} \mathrm{PEPIPICO}$ spectrum. $\mathrm{Left}_{\mathrm{C}} \mathrm{CH}_{2} \mathrm{Cl}^{+}$(ion 1) and SCN $($ion 2 ). Right: $\mathrm{CH}_{2}^{+}$(ion 1) and $\mathrm{SCN}^{+}$(ion 2).

Dynamics of Fragmentation for the $\mathrm{CH}_{2} \mathrm{CISCN}^{2+}$ Ion. Twodimensional PEPIPICO spectra for the correlation between one electron and two positive ions were recorded at each of the resonant energies values on the $S 2 p$ region. It is well-known that core excitation and core ionization lead to resonant and normal Auger processes, which are highly effective electronic decay mechanisms in promoting the dissociation of molecules. The analysis of the PEPIPICO spectra is useful for identifying two-, three-, ${ }^{30}$ and four-body dissociation mechanisms which especially follow Auger decay mechanisms. ${ }^{6,67}$

The experimental slopes for coincidence islands were determined at both resonance and off-resonance photon energies in the $S 2 p$ region and no significant changes in the dissociation mechanism were observed. The following discussion will be referred to slopes determined from the PEPIPICO spectrum taken at $165.9 \mathrm{eV}$ photon energy.

Fragmentation processes leading to the formation of $\mathrm{CH}_{2} \mathrm{Cl}^{+}$ and $\mathrm{SCN}^{+}$ions dominate the dissociation of $\mathrm{CH}_{2} \mathrm{ClSCN}$ excited at the $S 2 p$ levels. This coincidence represents the most intense island in the $155.0 \mathrm{eV}$ PEPIPICO spectrum, with a relative abundance of $16.8 \%$ (See Table 5). This value decreases when the photon energy reaches the resonant transition values. The typical parallelogram-like shape of the island and the observed slope of -1.0 (Figure 9) can be explained by a simple mechanism of fragmentation involving the rupture of the $\mathrm{C}-\mathrm{S}$ bond

$$
\mathrm{CH}_{2} \mathrm{ClSCN}^{2+} \rightarrow \mathrm{CH}_{2} \mathrm{Cl}^{+}+\mathrm{SCN}^{+}
$$

A similar two-body dissociation process was found for the $\mathrm{CH}_{3} \mathrm{SCN}$ species. $^{22}$

The coincidence between the $\mathrm{CH}_{2}^{+}$and the $\mathrm{SCN}^{+}$ions is also observed with the same slope $(-1.0)$, as shown in Figure 9. The

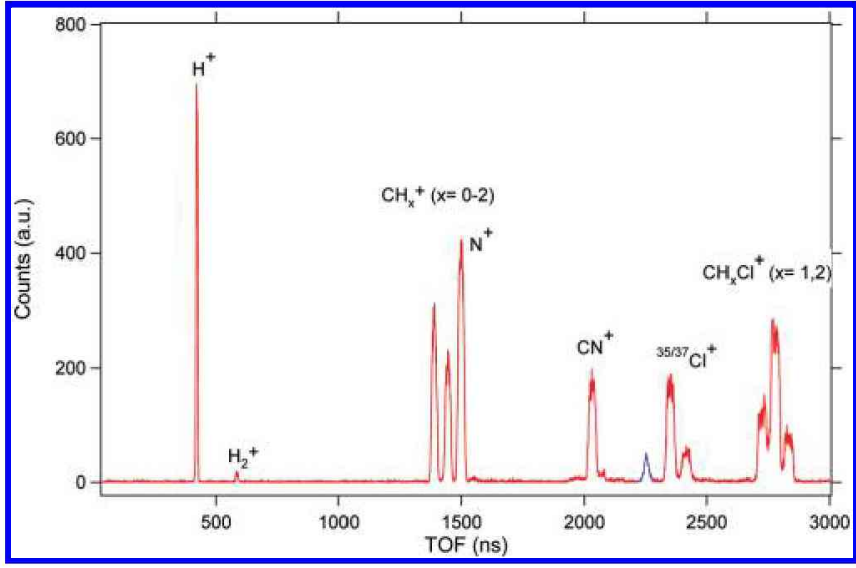

Figure 10. Projection of the $165.9 \mathrm{eV}$ PEPIPICO spectrum over the $\mathrm{S}^{+}$ arriving time for $\mathrm{CH}_{2} \mathrm{ClSCN}$.

three-body Coulombic explosion to form $\mathrm{CH}_{2}{ }^{+}+\mathrm{SCN}^{+}+\mathrm{Cl}$ can be postulated. However, when compared with the previous coincidence, the broadening in the peak shape is apparent, suggesting the occurrence of a deferred charge separation mechanism. The three-body reaction sequence involves the loss of a neutral fragment in the first step and the formation of the intermediate $\mathrm{CH}_{2} \mathrm{SCN}^{2+}$

$$
\begin{aligned}
& \mathrm{CH}_{2} \mathrm{ClSCN}^{2+} \rightarrow \mathrm{CH}_{2} \mathrm{SCN}^{2+}+\mathrm{Cl} \\
& \mathrm{CH}_{2} \mathrm{SCN}^{2+} \rightarrow \mathrm{CH}_{2}^{+}+\mathrm{SCN}^{+}
\end{aligned}
$$

When the S 2 p electrons are excited, the thiocyanate group undergoes a further dissociation process and several islands corresponding 


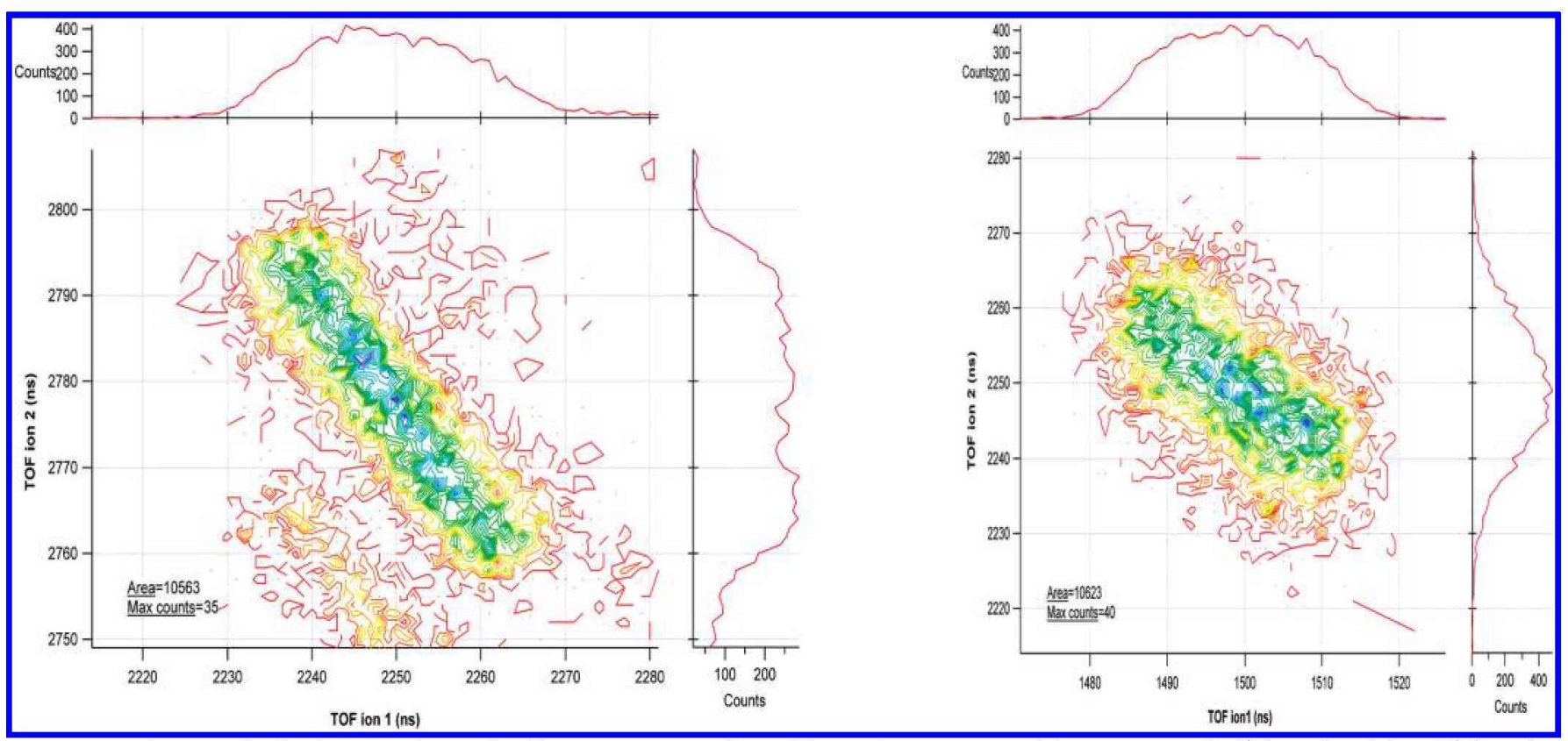

Figure 11. Contour plot for the coincidence island between ion pairs derived from $165.9 \mathrm{eV} \mathrm{PEPIPICO}$ spectrum. Left: $\mathrm{S}^{+}$(ion 1 ) and $\mathrm{CH}_{2} \mathrm{Cl}^{+}$(ion 2 ). Right: $\mathrm{CH}_{2}{ }^{+}$(ion 1) and $\mathrm{S}^{+}$(ion 2).

to the formation of $\mathrm{S}^{+}$atomic ions are observed. The importance of $\mathrm{S}^{+}$ ion contribution to the double coincidence spectra can be inferred from the projection spectrum showed in Figure 10 for times corresponding to ions arriving in the $2215-2280 \mathrm{~ns}$ range. Intense $\mathrm{H}^{+} / \mathrm{S}^{+}, \mathrm{CH}_{x}^{+} / \mathrm{S}^{+}(x=0-2)$, and $\mathrm{CN}^{+} / \mathrm{S}^{+}$coincidences, as well as coincidences between $\mathrm{S}^{+} / \mathrm{Cl}^{+}$and $\mathrm{S}^{+} / \mathrm{CH}_{x} \mathrm{Cl}^{+}(x=0-2)$, are anticipated (Table 5). Thus, as much as $28.1 \%$ of the double coincidences originated from $\mathrm{CH}_{2} \mathrm{ClSCN}$ have the $\mathrm{S}^{+}$ion either as the lightest $(11.8 \%)$ or as the second lightest $(16.3 \%)$ ion in the spectrum recorded at $155.0 \mathrm{eV}$. This contribution increases when the $\mathrm{Cl} 2 \mathrm{p}$ edge is reached, accounting for $30 \%$ at the $202.7 \mathrm{eV}$ ionization edge.

Two double coincidences $\mathrm{S}^{+} / \mathrm{CH}_{2} \mathrm{Cl}^{+}$and $\mathrm{CH}_{2}{ }^{+} / \mathrm{S}^{+}$showed in Figure 11, are of especial interest because they are intense islands in the whole range of photon energy here studied. The slope of the regression for arrival times of $\mathrm{S}^{+}$against $\mathrm{CH}_{2} \mathrm{Cl}^{+}$is -1.38 , suggesting the occurrence of a secondary decay scheme

$$
\begin{aligned}
& \mathrm{CH}_{2} \mathrm{ClSCN}^{2+} \rightarrow \mathrm{CH}_{2} \mathrm{Cl}^{+}+\mathrm{SCN}^{+} \\
& \mathrm{SCN}^{+} \rightarrow \mathrm{S}^{+}+\mathrm{CN}
\end{aligned}
$$

The expected slope value from the mass ratio is -1.81 , in moderate agreement with the experimental value. As commented by Eland ${ }^{66,67}$ for the dissociation of $\mathrm{OCS}^{2+}$, deviations of the regression slope from the nominal mass ratio expected for this sequential mechanisms indicates that the second charge separation process takes place within the range of the Coulomb field of the $\mathrm{CH}_{2} \mathrm{Cl}^{+}$ion.

In the reaction producing $\mathrm{CH}_{2}^{+}$and $\mathrm{S}^{+}$fragments a rather broad island is observed with a slope of -0.82 , as also shown in Figure 11. This coincidence is probably originated by a four-body dissociation process and following Simon et al. ${ }^{66,67}$ a secondary decay in competition can be postulated

$$
\begin{aligned}
& \mathrm{CH}_{2} \mathrm{ClSCN}^{2+} \rightarrow \mathrm{CH}_{2} \mathrm{Cl}^{+}+\mathrm{SCN}^{+} \\
& \mathrm{CH}_{2} \mathrm{Cl}^{+} \rightarrow \mathrm{CH}_{2}^{+}+\mathrm{Cl} \\
& \mathrm{SCN}^{+} \rightarrow \mathrm{S}^{+}+\mathrm{CN}
\end{aligned}
$$

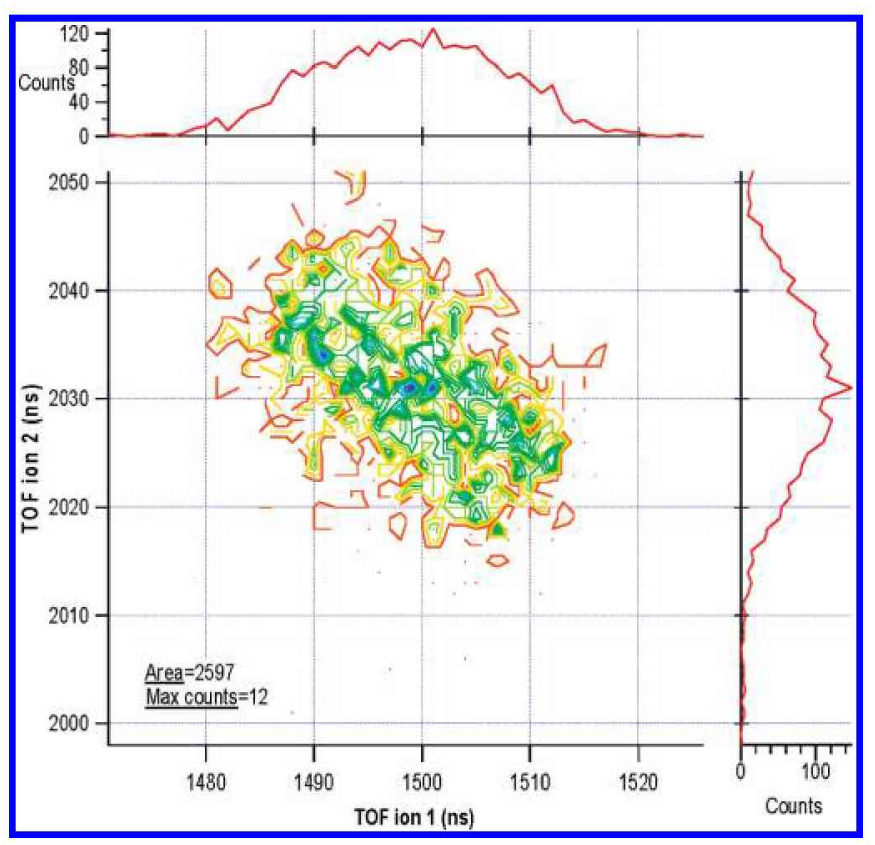

Figure 12. Contour plot for the coincidence island between ion pairs derived from $165.9 \mathrm{eV}$ PEPIPICO spectrum. $\mathrm{CN}^{+}$(ion 1) and $\mathrm{S}^{+}$(ion 2).

If the energy release associated with the neutral ejections are neglected, then the shape of the peak is a parallelogram with a slope given by the mass ratio $-(14 / 49) /(32 / 58)=-0.52$. It is possible that glancing collisions between the ions with the neutral fragments occur; in such a case the slope of the regression has an intermediate value between the -1 and the mass ratio. ${ }^{66,67}$ A concerted mechanism involving the simultaneous rupture of several bonds seems unlike.

The rupture of the $\mathrm{S}-\mathrm{C}$ bond of the thiocyanate group to yield $\mathrm{CN}^{+}$ions is responsible for ca. $8 \%$ of the fragmentation channels after $\mathrm{S} 2 \mathrm{p}$ ionizations of $\mathrm{CH}_{2} \mathrm{CISCN}^{2+}$. These dissociation pathways originated in the rupture of the $\mathrm{S}-\mathrm{CN}$ bond is 


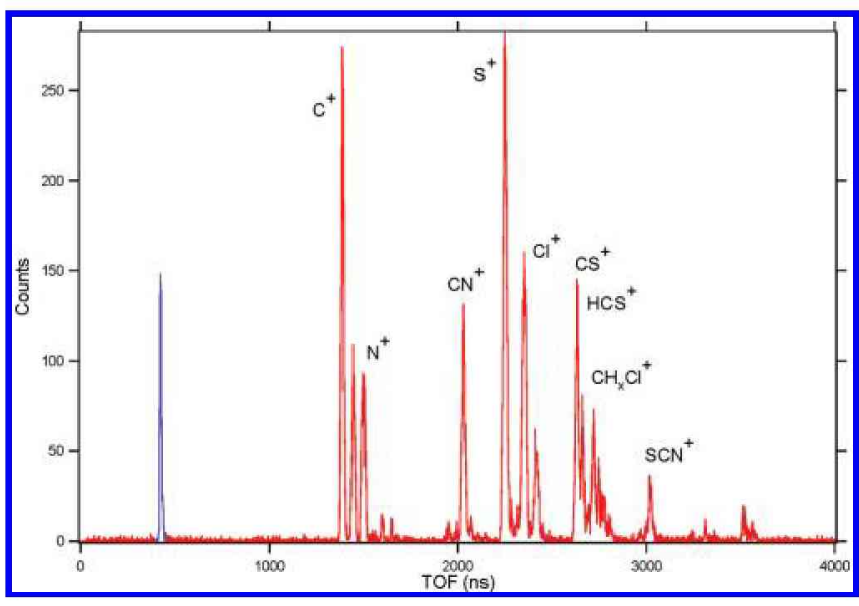

Figure 13. Projection of the $165.9 \mathrm{eV}$ PEPIPICO spectrum over the $\mathrm{H}^{+}$ arriving time for $\mathrm{CH}_{2} \mathrm{ClSCN}$.

responsible for the observation of the $\mathrm{CN}^{+} / \mathrm{S}^{+}$double coincidence with a slope of -1.1 (see Figure 12) and can be qualitatively sketched taking into account the following three-body dissociation mechanism

$$
\begin{aligned}
& \mathrm{CH}_{2} \mathrm{ClSCN}^{2+} \rightarrow \mathrm{CH}_{2} \mathrm{Cl}+\mathrm{SCN}^{2+} \\
& \mathrm{SCN}^{2+} \rightarrow \mathrm{S}^{+}+\mathrm{CN}^{+}
\end{aligned}
$$

The dynamic of the fragmentation of charged hydrocarbon species is strongly dominated by the rupture of $\mathrm{C}-\mathrm{H}$ bonds, thus, double coincidences involving the arrive of $\mathrm{H}^{+}$have been analyzed. The projection spectrum is shown in the Figure 13, and the observance of the ions with $m / z=12,13$, and 14 implies necessarily the coincidence with $\mathrm{C}^{+}, \mathrm{CH}^{+}$and $\mathrm{N}^{+}$ions. Moreover, the $\mathrm{H}^{+} / \mathrm{H}^{+}$coincidence is anticipated. As was early pointed out, it is difficult to obtain precise slope values for coincidences involving $\mathrm{H}^{+}$because of the unfavorable mass factor. ${ }^{66,67}$ As proposed by Montenegro et al. ${ }^{68}$ the processes that take place in ionized hydrocarbons can be characterized either as "evaporation", eliminating light $\mathrm{H}^{0}$ neutral atoms, or "fission", ejecting $\mathrm{H}^{+}$ ions, or the molecule can breaking up into two or more charged fragments. Both evaporation and fission processes are clearly observed in the valence continuum and $\mathrm{S} 2 \mathrm{p}$ excited $\mathrm{CH}_{3} \mathrm{SCN}$, whereas the presence of the chlorine atom in $\mathrm{CH}_{2} \mathrm{ClSCN}$ seems to favor the later process.

\section{CONCLUSIONS}

The HOMO of $\mathrm{CH}_{2} \mathrm{ClSCN}$ corresponds to a $\mathbf{n}_{\pi}(\mathrm{S})$ lone pair electrons, characterized as a narrow band in the photoelectron spectra. The fragmentation dynamic after valence ionization leads to the formation of $\mathrm{CH}_{2} \mathrm{Cl}^{+}$and $\mathrm{CH}_{2} \mathrm{SCN}^{+}$ions, in qualitative agreement with the assignment of the outermost orbital to $\mathbf{n}_{\pi}(\mathrm{S})$ and $\mathrm{n}(\mathrm{Cl})$ lone pair electrons.

The TIY spectrum of $\mathrm{CH}_{2} \mathrm{ClSCN}$ near the $\mathrm{S} 2 \mathrm{p}$ edge is very similar to those previously reported for $\mathrm{CH}_{3} \mathrm{SCN}^{22,21}$ and similar transitions can be anticipated. The fragmentation dynamics also show similarities with the related $\mathrm{CH}_{3} \mathrm{SCN}$ molecule. ${ }^{22,69,70}$ Thus, the two body dissociation mechanism yielding $\mathrm{CH}_{2} \mathrm{Cl}^{+}$and $\mathrm{SCN}^{+}$is observed with high intensity, together with other double coincidences that are originated by the rupture of the $\mathrm{C}-\mathrm{S}$ bond. Finally, the $\mathrm{HCS}^{+}$ion is also formed when $\mathrm{CH}_{2} \mathrm{ClSCN}$ is irradiated with photons in both the valence and inner shell region, reinforcing the observation that sulfur-containing methylated species are ubiquitous sources of this interesting interstellar ion.

\section{ASSOCIATED CONTENT}

5 Supporting Information. Atomic charge for the molecular and cation-radical form of $\mathrm{CH}_{2} \mathrm{ClSCN}$ is given in Table $\mathrm{S} 1$. Characters of the four lowest unoccupied orbitals are given in Figure S1. This material is available free of charge via the Internet at http://pubs.acs.org.

\section{AUTHOR INFORMATION}

\section{Corresponding Author}

${ }^{*} \mathrm{Tel} / \mathrm{Fax}$ :+54-221-425-9485. E-mail: erben@quimica.unlp. edu.ar (M.F.E.); carlosdv@quimica.unlp.edu.ar (C.O.D.V.).

\section{ACKNOWLEDGMENT}

L.S.R.P. is a doctoral fellow of CONICET. M.G., R.M.R, C.O. D.V., A.F., and M.F.E. are members of the Carrera del Investigador of CONICET. This work has been largely supported by the Brazilian Synchrotron Light Source (LNLS) under proposal D05A-TGM-8230. The authors thank Arnaldo Naves de Brito and his research group for fruitful discussions and generous collaboration during their several stays in Campinas and the TGM beamline staff for their assistance throughout the experiments. They are indebted to the Agencia Nacional de Promoción Científica y Tecnológica (ANPCyT), Consejo Nacional de Investigaciones Cientificas y Técnicas (CONICET), and the Comisión de Investigaciones Científicas de la Provincia de Buenos Aires (CIC), República Argentina, for financial support. They also thank the Facultad de Ciencias Exactas, Universidad Nacional de La Plata, República Argentina for financial support.

\section{REFERENCES}

(1) Erian, A. W.; Sherif, S. M. Tetrahedron 1999, 55, 7957.

(2) Sharma, S. L. Sulfur Chem. 1989, 8, 327.

(3) Magnus, P. D. Tetrahedron 1977, 33, 2019.

(4) Mehta, R. G.; Liu, J.; Constantinou, A; Thomas, C. F.; Hawthorne, M.; You, M.; Gerhauser, C.; Pezzuto, J. M.; Moon, R. C.; Moriarty, R. M. Carcinogenesis 1995, 16, 399.

(5) Muthusubramanian, L; Mitra, R. B. LSoc. Leather Technol Chem. 2003, 87,115 .

(6) Muthusubramanian, L.; Mitra, R. B.; Rajkumar, S.; Sundara Rao, V. S. J. Chem. Technol. Biotechnol. 1998, 11, 695.

(7) Brand, W. W.; Gullo, J. M.; Carr, M. C. Phosohorus Sultur Rel. Elem. 1981, 10, 183.

(8) Al-Rawi, J. M. A.; David, R. Y.; Elvidge, J. A. L. Chem. Soc..Perkin Trans. 1 1982, 10, 2499.

(9) Zhao, Y.; Sun, Y.; Sun, J;; Fang, W.; Shan, X.; Liu, F.; Sheng, L.; Wang, Z. LElectron Spectrosc, Relat. Phenom. 2009, 173, 24.

(10) Crowder, G. A. L. Chem. Phys. 1967, 47, 3080.

(11) Crowder, G. A. Spectrosc. Lett. 1986, 19, 713.

(12) Mölder, U. H.; Pikver, R. J.; Koppel, I. A. Oro. React. (Tartu) 1983, 20, 230

(13) Erben, M. F.; Romano, R. M.; Della Védova, C. O. L.Phws. Chem. A 2004, 108, 3938.

(14) Erben, M. F.; Romano, R. M.; Della Védova, C. O. L.Phus. Chem. A 2005, 109, 304.

(15) Erben, M. F.; Geronés, M.; Romano, R. M.; Della Védova, C. O. LPhus. Chem.A 2006, 110, 875.

(16) Rodríguez Pirani, L. S.; Erben, M. F.; Geronés, M.; Ma, C.; Ge, M.; Romano, R. M.; Cavasso Filho, R. L.; Della Védova, C. O. L.Phys. Chem.A 2011, 115, 5307. 
(17) Erben, M. F.; Geronés, M.; Romano, R. M.; Della Védova, C. O. L. Phus. Chem. A 2007, 111, 8062.

(18) Geronés, M.; Erben, M. F.; Romano, R. M.; Della Védova, C. O.; Yao, L.; Ge, M. L.Phvs. Chem. A 2008, 112, 2228.

(19) Erben, M. F.; Della Védova, C. O. Inorg. Chem. 2002, 41, 3740.

(20) Geronés, M.; Downs, A. J.; Erben, M. F.; Ge, M.; Romano,

R. M.; Yao, L.; Della Védova, C. O. I. Phys. Chem. A 2008, 112, 5947.

(21) Hitchcock, A. P.; Tronc, M.; Modelli, A. L.Phus. Chem. 1989, 93, 3068.

(22) Cortés, E.; Erben, M. F.; Geronés, M.; Romano, R. M.; Della Védova, C. O. L. Phus. Chem. A 2009, 113, 564.

(23) Lira, A. C.; Rodrigues, A. R. D.; Rosa, A.; Gonçalves da Silva, C. E. T.; Pardine, C.; Scorzato, C.; Wisnivesky, D.; Rafael, F.; Franco, G. S.; Tosin, G.; Lin, L.; Jahnel, L.; Ferreira, M. J.; Tavares, P. F.; Farias, R. H. A; Neuenschwander, R. T. "First Year Operation of the Brazilian Sinchrotron Light Source"; European Particle Accelerator Conference, 1998, Stockholm.

(24) de Fonseca, P. T.; Pacheco, J. G.; Samogin, E.; de Castro,

A. R. B. Rev. Sci. Instrum. 1992, 63, 1256.

(25) Burmeister, F.; Coutinho, L. H.; Marinho, R. R. T.; Homem, M. G. P.; de Morais, M. A. A.; Mocellin, A.; Björneholm, O.; Sorensen, S. L.; Fonseca, P. T.; Lindgren, A.; Naves de Brito, A. LElectron Spectrose. Belat. Phenom. 2010, 180, 6.

(26) Kivimaki, A.; Ruiz, J. A.; Erman, P.; Hatherly, P.; Garcia, E. M.; Rachlew, E.; Rius i Riu, J.; Stankiewicz, M. L.Phys. B 2003, 781.

(27) Cavasso Filho, R. L.; Homem, M. G. P.; Landers, R.; Naves de Brito, A. I.Electron Spectrosc. Relat. Phenom. 2005, 144-147, 1125.

(28) Cavasso Filho, R. L.; Lago, A. F.; Homem, M. G. P.; Pilling, S.; Naves de Brito, A. I. Electron Spectrosc. Relat. Phenom. 2007, 156-158, 168.

(29) Cavasso Filho, R. L.; Homen, M. G. P.; Fonseca, P. T.; Naves de Brito, A. Rev. Sci. Instrum. 2007, 78, 115104.

(30) Frasinski, L. J.; Stankiewicz, M.; Randall, K. J.; Hatherly, P. A.; Codling, K. L. Phvs. B 1986, 19, L819.

(31) Eland, J. H. D.; Wort, F. S.; Royds, R. N. L. Electron Spectrosc. Relat. Phenom. 1986, 41, 297.

(32) Naves de Brito, A; Feifel, R.; Mocellin, A.; Machado, A. B.; Sundin, S.; Hjelte, I.; Sorensen, S. L.; Bjorneholm, O. Chem. Phus. Lett. 1999, 309, 377.

(33) Laskin, J.; Lifshitz, C. L. Mass Spectrom. 2001, 36, 459.

(34) Simon, M.; LeBrun, T.; Morin, P.; Lavollée, M.; Maréchal, J. L. Nucl. Instrum. Methods 1991, B62, 167.

(35) Santos, A. C. F.; Lucas, C. A.; de Souza, G. G. B. I. Electron Spectrosc. Relat. Phenom. 2001, 114-116, 115.

(36) Zeng, X.; Ge, M.; Sun, Z.; Bian, J.; Wang, D. I. Mol. Struct. 2007, 840,59 .

(37) Yao, L.; Zeng, X.; Ge, M.; Wang, W.; Sun, Z.; Du, L.; Wang, D. Eur. I. Inorg. Chem. 2006, 2469.

(38) Wang, W.; Yao, L.; Zeng, X.; Ge, M.; Sun, Z.; Wang, D.; Ding, Y. I. Chem. Phys. 2006, 125, 234303.

(39) Li, Y.; Zeng, X.; Sun, Q.; Li, H.; Ge, M.; Wang, D. Snectrochim. ActaA 2007, 66, 1261.

(40) Tarantelli, F.; Cederbaum, L. S. Phws.Rev.Lett. 1993, 71, 649.

(41) DeFrees, D. J.; Binkley, J. S.; Frisch, M. J.; McLean, A. D. I. Chem. Phvs. 1986, 85, 5194.

(42) Hiroshi, N.; Tomoo, M.; Ryoichi, F. L.Chem. Phws. 2007, 126, 084104 .

(43) Deleuze, M. S.; Knippenberg, S. I. Chem. Phws. 2006, 125, 104309 .

(44) Morini, F.; Knippenberg, S.; Deleuze, M. S.; Hajgato, B. L.Phys. Chem. A 2010, 114, 4400.

(45) Rodríguez Pirani, L.; Erben, M. F.; Boese, R.; Della Védova, C. O. Unpublished results.

(46) Boese, R.; Nussbaumer, M. In situ Crystallisation Techniques. In Organic Crystal Chem.; Jones, D. W., Ed.; Oxford University Press: Oxford, 1994; Vol. 7, p 20.

(47) Mölder, U.; Pikver, R.; Koppel, I. Org.React. (Tartu) 1983, 20, 355 .

(48) Pasinszki, T.; Veszprèmi, T.; Fehèr, M.; Kovac, B.; Klasinc, L.; Mcglynn, S. P. Int. I. Ouantum Chem. 1992, 26, 443.
(49) Rodríguez Pirani, L. S.; Geronés, M.; Della Védova, C. O.; Romano, R. M.; Fantoni, A.; Cavasso-Filho, R.; Ma, C.; Ge, M.; Erben, M. F. To be published.

(50) Frost, D. C.; Herring, F. G.; Katrib, A.; McDowell, C. A.; McLean, R. A. N. L. Phys. Chem. 1972, 76, 1030.

(51) Byrd, E. F. C.; Sherrill, C. D.; Head-Gordon, M. L.Phus. Chem. A 2001, 105, 9736 .

(52) Cradock, S.; Ebsworth, E. A. V.; Murdoch, J. D. L. Chem. Soc. Earadaw Trans. 2 1972, 68, 86.

(53) Zakrzewski, V. G.; Ortiz, J. V.; Nichols, J. A.; Heryadi, D.; Yeager, D. L.; Golab, J. T. Int.I. Ouantum Chem. 1996, 60, 29.

(54) Deleuze, M. S. Chem. Phws. 2006, 329, 22.

(55) Stein, S. E. NIST Mass Spec. Data Center, NIST Standard Reference Database Number 69, March 2003, National Institute of Standards and Technology; Linstrom, P. J., Mallard, W. G., Eds.; National Institute of Standards and Technology: Gaithersburg, MD, 2003.

(56) Nenner, I.; Beswick, J. A. Molecular Photodissociation and Photoionization. In Handbook on Synchrotron Radiation; Marr, G. V., Ed.; Elsevier Science Publishers: Amsterdam, 1987; Vol. 2, p 355.

(57) Cortés, E.; Della Védova, C. O.; Geronés, M.; Romano, R. M.; Erben, M. F. I. Phws. Chem. A 2009, 113, 9624.

(58) Thissen, R; Simon, M.; Hubin-Franskin, M.-J. L. Chem. Phus. $1994,101,7548$.

(59) Geronés, M.; Erben, M. F.; Ge, M.; Cavasso Filho, R. L.; Romano, R. M.; Della Védova, C. O. I. Phys. Chem. A 2010, 114, 8049.

(60) Geronés, M.; Erben, M. F.; Romano, R. M.; Cavasso Filho,

R. L.; Della Védova, C. O. I. Phys. Chem. A 2010, 114, 12353.

(61) Thaddeus, P.; Guélin, M.; Linke, R. A. Astrophws.I. 1981, 246, L41.

(62) Gudeman, C. S.; Haese, N. N.; Piltch, N. D.; Woods, R. C. Astrophys. J. 1981, 246, L47.

(63) Bogey, M.; Demuynck, C.; Destombes, J. L.; Lemoine, B. L.Mol. Spectrose. 1984, 107, 417.

(64) Margulès, L.; Lewen, F.; Winnewisser, G.; Botschwina, P.; Müller, H. S. P. Phrs. Chem. Chem. Phvs. 2003, 5, 2770.

(65) Smith, D. Chem. Rev. 1992, 92, 1473.

(66) Eland, J. H. D. Mol. Phvs. 1987, 61, 725.

(67) Simon, M.; Lebrun, T.; Martins, R.; de Souza, G. G. B.; Nenner, I.; Lavollee, M.; Morin, P. L. Phws. Chem. 1993, 97, 5228.

(68) Montenegro, E. C.; Scully, S. W. J.; Wyer, J. A.; Senthil, V.; Shah, M. B. L.Electron Suectrosc. Relat. Phenom. 2007, 155, 81.

(69) Tokue, I.; Hiraya, A.; Shobatake, K. Chem. Phus. 1987, 117, 315.

(70) Tokue, I.; Kobayashi, K.; Honda, T.; Ito, Y. L.Phws. Chem. 1990, 94,3485 . 